\title{
Plasma membrane perforation by GSDME during apoptosis-driven secondary necrosis
}

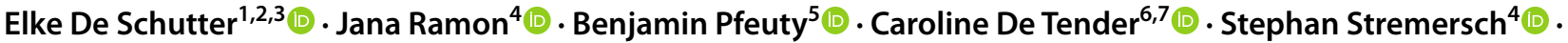

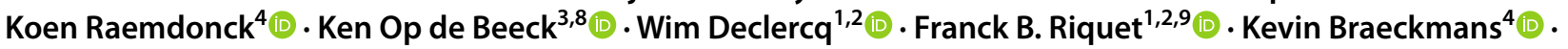 \\ Peter Vandenabeele ${ }^{1,2}$ (B)
}

Received: 3 June 2021 / Revised: 14 October 2021 / Accepted: 19 October 2021 / Published online: 31 December 2021

(c) The Author(s) 2021

\begin{abstract}
Secondary necrosis has long been perceived as an uncontrolled process resulting in total lysis of the apoptotic cell. Recently, it was shown that progression of apoptosis to secondary necrosis is regulated by Gasdermin E (GSDME), which requires activation by caspase-3. Although the contribution of GSDME in this context has been attributed to its pore-forming capacity, little is known about the kinetics and size characteristics of this. Here we report on the membrane permeabilizing features of GSDME by monitoring the influx and efflux of dextrans of different sizes into/from anti-Fas-treated L929sAhFas cells undergoing apoptosis-driven secondary necrosis. We found that GSDME accelerates cell lysis measured by SYTOX Blue staining but does not affect the exposure of phosphatidylserine on the plasma membrane. Furthermore, loss of GSDME expression clearly hampered the influx of fluorescently labeled dextrans while the efflux happened independently of the presence or absence of GSDME expression. Importantly, both in- and efflux of dextrans were dependent on their molecular weight. Altogether, our results demonstrate that GSDME regulates the passage of compounds together with other plasma membrane destabilizing subroutines.
\end{abstract}

Keywords Gasdermins $\cdot$ Cell death $\cdot$ Membrane permeabilization $\cdot$ Influx $\cdot$ Efflux $\cdot$ Dextrans

Elke De Schutter and Jana Ramon (shared first authorship) contributed equally to this work.

Franck B. Riquet, Kevin Braeckmans and Peter Vandenabeele share senior authorship.

Peter Vandenabeele

Peter.Vandenabeele@irc.vib-ugent.be

1 VIB Center for Inflammation Research, 9052 Ghent, Belgium

2 Department of Biomedical Molecular Biology, Ghent University, 9052 Ghent, Belgium

3 Center of Medical Genetics, University of Antwerp and Antwerp University Hospital, 2650 Antwerp, Belgium

4 Laboratory of General Biochemistry and Physical Pharmacy, Faculty of Pharmaceutical Sciences, Ghent University, 9000 Ghent, Belgium

\section{Introduction}

Apoptosis, the best-known form of regulated cell death, is essentially a containment and recycling program that prepares the cell corpse for efficient phagocytosis [1]. However, when phagocytes are absent or the phagocytic capacity is insufficient, apoptotic cells progress to necrotic plasma membrane permeabilization called apoptosis-driven secondary necrosis, which results in a more inflammatory

5 Université de Lille, CNRS, UMR 8523-PhLAM-Physique des Lasers Atomes et Molécules,, 59000 Lille, France

6 Department of Applied Mathematics, Computer Science and Statistics, Ghent University, 9000 Ghent, Belgium

7 Plant Sciences Unit, Flanders Research Institute for Agriculture, Fisheries and Food, 9820 Merelbeke, Belgium

8 Center for Oncological Research, University of Antwerp and Antwerp University Hospital, 2610 Antwerp, Belgium

9 Université de Lille, 59000 Lille, France 
environment [2-5]. The gasdermin (GSDM) protein family gained a lot of interest as plasma membrane permeabilizers during regulated cell death [6-8]. Gasdermin D (GSDMD) is proteolytically activated by caspase- 1 and -4 leading to inflammasome-mediated pyroptosis $[9,10]$ and the GSDMD-dependent release of pro-inflammatory cytokines such as interleukin-1 $\beta$ [11]. Similarly, apoptosis-driven secondary necrosis is driven by the activation of gasdermin $\mathrm{E}$ (GSDME) [12, 13]. To entail its effect, caspase-3-mediated cleavage induces the release of GSDME's cytotoxic N-terminal p30 fragment from the auto-inhibiting C-terminal domain, which is followed by plasma membrane recruitment and plasma membrane permeabilization $[12,14,15]$. Nevertheless, GSDME may not be the only mechanism responsible for secondary necrosis. GSDME expression is dispensable for secondary necrosis following NLRC4-mediated apoptosis in macrophages [16] or UV irradiation-induced apoptosis in human T cells and monocytes [17].

After cleavage, GSDM proteins were shown to oligomerize and bind to plasma membrane phospholipids [14, 18], suggesting that GSDMs establish plasma membrane permeabilization by perforation. Moreover, the structure of GSDMD and mouse GSDMA3 revealed more mechanistic insights in how the $\mathrm{N}$-terminal domain is able to form pores $[19,20]$. Using cryo-electron microscopy, it was discovered that the N-terminal domains of GSDMA3 form a large, 27 -fold $\beta$-barrel-stave protein pore with an inner diameter of $18 \mathrm{~nm}$ [19]. In addition, 26- and 28-fold oligomerization structures were reported with similar dimensions as the dominant 27-subunit GSDMA3 pore [19]. In contrast, GSDMD assemblies were reported to have a 31- to 34-fold symmetry [20], suggesting significant variability in oligomerization among different GSDM proteins. In addition, the $\mathrm{N}$-terminal domain of GSDMD assembles into dynamic arc- and slit-shaped oligomers before they finally transform to stable ring-shaped oligomers with varying diameters ranging from 13.5 till $33.5 \mathrm{~nm}[21,22]$.

Unlike GSDMA3 and GSDMD, the characteristics of GSDME pore formation are currently unknown. Therefore, to gain insight into the membrane permeabilizing behavior of GSDME and its role in apoptosis-driven secondary necrosis, we applied two in vitro approaches. With the assumption that GSDME forms pores in the plasma membrane, influx or efflux of macromolecules, such as fluorescently labeled dextrans, is expected to happen when cells are exposed to apoptotic stimuli. Monitoring the uptake of fluorescently labeled dextrans in apoptotic cells is quite straightforward, only requiring the addition of the dextrans to the culture medium after apoptosis induction. However, monitoring efflux is less obvious as the cells should be pre-loaded with the dextrans in a manner that does not interfere with cellular processes such as proliferation or without inducing apoptosis by itself. Therefore, we selected nanoparticle-sensitized photoporation, which is an emerging intracellular delivery technique that enables direct cytosolic delivery of membrane-impermeable macromolecules in virtually every cell type with minimal impact on the cellular homeostasis [23-29]. This technique makes use of photothermal nanoparticles, such as gold nanoparticles (AuNPs), which are incubated with cells and bind to the plasma membrane. Upon irradiation by a short, yet intense laser pulse, the AuNPs become heated, resulting in the evaporation of the surrounding water and the formation of quickly expanding water vapor nanobubbles (VNBs) around the AuNPs. The mechanical forces resulting from the expansion and collapse of those VNBs lead to the generation of localized pores in the plasma membrane [27, 30]. Through those transient plasma membrane pores, which are repaired within seconds to minutes, an exchange of molecules between the intraand extracellular compartment can happen [25, 26, 28, 29]. Importantly, under controlled conditions, complete cellular recovery is reported within $24 \mathrm{~h}$ upon laser treatment with minimal effect on the cellular homeostasis [23, 24, 26].

Here, we studied the membrane permeabilizing behavior of GSDME during apoptosis-driven secondary necrosis and attempted to elucidate whether this process is characterized by discrete pore sizes and/or whether GSDME pores grow over time. To this end, we developed GSDME-deficient L929sAhFas cells carrying a doxycycline-inducible system for GSDME expression allowing the exploration of secondary necrosis in the absence or presence of GSDME in the same cellular context. We reveal that the absence of GSDME delays nuclear staining by SYTOX Blue (SB), as cells remain longer in the sublytic phase, while phosphatidylserine (PS) exposure was not affected. Next, we investigated the involvement of GSDME in the influx and efflux of fluorescently labeled dextrans of different sizes during apoptosisdriven secondary necrosis induced by anti-Fas. We provide evidence that pore formation during apoptosis-driven secondary necrosis is a gradual process that already supports a GSDME-dependent influx of fluorescently labeled dextrans before the nuclear DNA of dying cells is stained by SB. Furthermore, the influx method allowed us to make an estimation of molecular sizes able to pass the GSDME pore. In contrast, efflux of fluorescently labeled dextrans seemed to occur independently of GSDME combined with the fact that only significant dextran loss was observed when cells were already stained by SB.

\section{Materials and methods}

\section{Cell culture}

L929sAhFas cells and derivates were cultured in Dulbecco's Modified Eagle Medium supplemented with $10 \%$ of Fetal 
Bovine Serum (v/v), L-glutamine ( $2 \mathrm{mM}$ ) and sodium pyruvate $(400 \mathrm{mM})$. Cells were cultured in $37^{\circ} \mathrm{C}$ in a humidified atmosphere containing $5 \% \mathrm{CO}_{2}$ and were regularly tested against mycoplasma contamination.

\section{Generation of gasdermin E-deficient L929sAhFas cells}

Single guide RNAs (sgRNA) targeting the exon 4 of Gsdme were selected using the Wellcome Trust Sanger Institute Genome Editing database (WGE) [31] and were manufactured by Thermo Fischer Scientific. The sgRNA sequences are listed in Supplementary Table S1. The sgRNA oligo sequence was cloned in BpiI-digested pSpCas9(BB)-2AGFP carrying Streptococcus pyogenes WT Cas9 (Addgene, plasmid no. 48138). The sgRNA Cas9 plasmid was transfected into L929sAhFas cells via jetPRIME transfection reagent (Polyplus-transfection). $4 \mu \mathrm{g}$ plasmid was added per 25000 cells and incubated for $4 \mathrm{~h}$ at $37{ }^{\circ} \mathrm{C}, 5 \% \mathrm{CO}_{2}$ after which the culture medium was replaced and cells were further incubated for 4 days at $37{ }^{\circ} \mathrm{C}, 5 \% \mathrm{CO}_{2}$. Next, cells were harvested and GFP-positive cells were sorted using a FACSAria III (BD Biosciences). Effective genomic interruption of Gsdme was confirmed with PCR and Sanger sequencing. Allele editing was analyzed using TIDE [32]. The PCR and sequencing primers used are listed in Supplementary Table S1.

\section{Generation of a stable gasdermin E-inducible L929sAhFas cell line}

The L929sAhFas iGSDME cell line was obtained by transduction of Gsdme KOcl2 L929sAhFas cells with a pDG2mGSDME-blast plasmid. This is a tetracycline-inducible derivative of pLenti6 (Life Technologies) containing a blasticidin selection marker [33], in which the coding sequence of murine GSDME was cloned. Upon lentiviral transduction, the stably transduced cells were selected with $5-10 \mu \mathrm{g} / \mathrm{ml}$ blasticidin.

\section{Analysis of phosphatidylserine exposure and cell death kinetics}

L929sAhFas iGSDME cells were seeded in 24-well suspension plates $\left(100 \times 10^{3}\right.$ cells/well $)$ in the presence or absence of doxycycline (Sigma-Aldrich, $1 \mu \mathrm{g} / \mathrm{ml}$ ) and stimulated the next day with $125 \mathrm{ng} / \mathrm{ml}$ anti-Fas (clone CH11, Upstate). Cell death parameters were analyzed after incubation between $0 \mathrm{~h}$ and $10 \mathrm{~h}$ of anti-Fas treatment. $1 \mathrm{~h}$ before measurement, fluorescent probes were added to the culture medium: $1.25 \mu \mathrm{M}$ of SYTOX Blue nucleic acid stain and $7.5 \mathrm{nM}$ of Annexin V Alexa Fluor 488 conjugate (Molecular Probes). Subsequently, samples were measured by flow cytometry using a four-laser BD Fortessa or three-laser BD LSR II (BD Biosciences) and data were analyzed using FlowJo 10.7.1.

\section{Western blotting}

L929sAhFas iGSDME cells were pretreated with $1 \mu \mathrm{g} / \mathrm{ml}$ doxycycline (Sigma-Aldrich) to allow GSDME expression. L929sAhFas and L929sAhFas iGSDME cells were incubated for $8 \mathrm{~h}$ with $250 \mathrm{ng} / \mathrm{ml}$ anti-Fas (clone CH11, Upstate) at $37{ }^{\circ} \mathrm{C}, 5 \% \mathrm{CO}_{2}$, after which they were harvested and washed twice in ice-cold phosphate-buffered saline (PBS). Next, cells were lysed using ice-cold RIPA lysis buffer (50 mM Tris-HCl; pH 7.5; $150 \mathrm{mM} \mathrm{NaCl} ; 1 \mathrm{mM}$ EDTA; $0.5 \%$ sodium deoxycholate; $1 \%$ Triton X-100 and $0.1 \%$ SDS) freshly supplemented with EDTA-free complete protease inhibitor cocktail tablets and phosphatase inhibitor cocktail tablets (Roche Diagnostics Belgium N.V.). Extracted proteins were separated on $12 \%$ sodium dodecyl sulfate (SDS) polyacrylamide gels and transferred onto nitrocellulose membranes (Amersham Bioscience). Membranes were blocked using Tris-buffered saline containing $0.05 \%$ Tween ${ }^{\circledR} 20$ (TBS-T) and 5\% non-fat dry milk (Biorad) followed by incubation with anti-GSDME (ab215191, abcam) or anti-actin (69100, MP Biomedicals) antibodies. After incubation with the horseradish peroxidase (HRP)linked donkey anti-rabbit IgG or HRP-linked sheep antimouse (Amersham Biosciences), blots were revealed using a Western Lightning Plus-ECL (PerkinElmer).

\section{Intracellular delivery of FITC-labeled dextrans by nanoparticle-sensitized photoporation}

AuNPs with a core size of $60 \mathrm{~nm}$ were in-house synthetized using the Turkevich method and coated with the cationic polymer poly(diallyldimethylammonium chloride) (PDDAC) as reported before [34].

To determine the AuNP concentration that provides optimal photoporation results, L929sAhFas $\left(130 \times 10^{3}\right)$ were seeded in 24-well plates and allowed to attach overnight at $37{ }^{\circ} \mathrm{C}, 5 \% \mathrm{CO}_{2}$. Next, cells were incubated for $30 \mathrm{~min}$ $\left(37{ }^{\circ} \mathrm{C}, 5 \% \mathrm{CO}_{2}\right)$ with different concentrations of AuNPs (2, 4, 6,8 and $16 \times 10^{7}$ AuNPs/mL), washed with PBS to remove unbound AuNPs, and replenished with fresh culture medium containing $5 \mathrm{mg} / \mathrm{ml}$ FITC-labeled dextrans (SigmaAldrich) of $10 \mathrm{kDa}$ (FD10). Subsequently, cells were photoporated using an in-house built laser irradiation set-up equipped with a nanosecond pulsed laser ( $5 \mathrm{~ns}$ pulse duration, $\lambda=532 \mathrm{~nm}$, Tor, Cobolt) and a galvano scanner (Thorlabs, THORLABS-GVS002.SLDPRT) for rapid beam scanning across the samples. A fixed laser pulse fluence (optical energy per unit area) of $0.86 \mathrm{~J} / \mathrm{cm}^{2}$ was applied. After laser treatment, FD10-diluted medium was removed and cells 
were washed twice with culture medium and once with PBS followed by cell detachment using $0.25 \%$ trypsin-EDTA. At last, cells were measured for their FD10 content by flow cytometry using a three-laser BD LSR II (BD biosciences) and data were analyzed using FlowJo 10.7.1.

For loading with FITC-labeled dextrans in the function of efflux experiments, L929s AhFas iGSDME cells $\left(650 \times 10^{3}\right.$ cells/well) were seeded in 6-well plates and allowed to attach overnight at $37{ }^{\circ} \mathrm{C}, 5 \% \mathrm{CO}_{2}$. The same protocol as described before was used. In this case, cells were incubated with the optimal AuNP concentration $\left(6 \times 10^{7}\right.$ AuNPs/ml) for $30 \mathrm{~min}$. After washing away of unbound AuNPs, culture medium was added containing FITC-labeled dextrans (Sigma-Aldrich) of $4 \mathrm{kDa}$ (FD4), $10 \mathrm{kDa}$ (FD10), $40 \mathrm{kDa}$ (FD40), $70 \mathrm{kDa}$ (FD70), $150 \mathrm{kDa}$ (FD150), $250 \mathrm{kDa}$ (FD250), $500 \mathrm{kDa}$ (FD500) or $2000 \mathrm{kDa}$ (FD2000). For all sizes, a concentration of $5 \mathrm{mg} / \mathrm{ml}$ was used, except for $2000 \mathrm{kDa}$ for which the concentration was increased to $10 \mathrm{mg} / \mathrm{ml}$. Cells were subsequently photoporated using a fixed laser pulse fluence of $0.86 \mathrm{~J} / \mathrm{cm}^{2}$ after which the dextran-containing medium was removed and cells were washed twice with culture medium. After $2 \mathrm{~h}$ of incubation $\left(37^{\circ} \mathrm{C}\right.$ and $\left.5 \% \mathrm{CO}_{2}\right)$, the same procedure was repeated a second time to further increase the percentage of fluorescently labeled cells. Finally, cells were detached using $0.25 \%$ trypsin-EDTA and re-seeded at $100 \times 10^{3}$ cells/well in 24 -well suspension plates in the presence or absence of doxycycline (Sigma-Aldrich, $1 \mu \mathrm{g}$ / $\mathrm{ml})$ and allowed to grow overnight $\left(37^{\circ} \mathrm{C}, 5 \% \mathrm{CO}_{2}\right)$.

\section{Influx and efflux of fluorescently labeled dextrans and cell death analysis}

For influx experiments, L929sAhFas iGSDME cells were seeded in 24-well suspension plates $\left(100 \times 10^{3}\right.$ cells/well $)$ in the presence or absence of doxycycline (Sigma-Aldrich, $1 \mu \mathrm{g} / \mathrm{ml}$ ) and treated the next day with $250 \mathrm{ng} / \mathrm{ml}$ anti-Fas (clone CH11, Upstate) for $10 \mathrm{~h}$ every $2 \mathrm{~h}$. Afterwards, cells were harvested by gently pipetting up and down and were immediately centrifuged at $400 \mathrm{~g}$ for $5 \mathrm{~min}$ at $4{ }^{\circ} \mathrm{C}$. After removing the supernatant, the cells were resuspended in culture medium containing $0.5 \mathrm{mg} / \mathrm{ml}$ Texas Red-labeled dextrans (Invitrogen and Nanocs) of $10 \mathrm{kDa}$ (TR10), $40 \mathrm{kDa}$ (TR40), $70 \mathrm{kDa}$ (TR70) or $2000 \mathrm{kDa}$ (TR2000) and incubated for $5 \mathrm{~min}$ at room temperature. Next, cells were centrifuged again for $5 \mathrm{~min}$ at $400 \mathrm{~g}$ and $4{ }^{\circ} \mathrm{C}$, washed and resuspended in culture medium containing $2.5 \mu \mathrm{M}$ SYTOX Blue (Molecular Probes) for nuclear staining. Samples were subsequently measured by flow cytometry using a four-laser BD Fortessa (BD Biosciences) and data were analyzed using FlowJo 10.7.1.

For efflux experiments, L929sAhFas iGSDME cells were preloaded with FITC-labeled dextrans (Sigma-Aldrich) using nanoparticle-sensitized photoporation and re-seeded in 24-well suspension plates in the presence or absence of doxycycline (Sigma-Aldrich, $1 \mu \mathrm{g} / \mathrm{ml}$ ). One day after photoporation, re-seeded L929sAhFas iGSDME were treated with $250 \mathrm{ng} / \mathrm{ml}$ anti-Fas (clone CH11, Upstate) for $10 \mathrm{~h}$ every $2 \mathrm{~h}$. Subsequently, cells were stained with SYTOX blue (Molecular probes) at a concentration of $2.5 \mu \mathrm{M}$ after which they were collected by gently pipetting up and down and measured by flow cytometry using a three-laser BD LSR II (BD Biosciences). Data were analyzed using FlowJo 10.7.1.

\section{CellTiter-Glo ${ }^{\circledast}$ cell viability assay}

In view of determining the optimal AuNP concentration, cell viability was assessed $2 \mathrm{~h}$ after laser treatment using the CellTiter-Glo® luminescent cell viability assay (Promega) following the manufacturer's protocol. Briefly, the culture medium was replaced by equal amounts of fresh culture medium and CellTiter-Glo® reagent and cells were mixed for $30 \mathrm{~min}$ using an orbital shaker at $120 \mathrm{rpm}$. After allowing stabilization of the luminescent signal for $15 \mathrm{~min}$, equal volumes of each well were transferred to an opaque well plate and luminescence was recorded by a GloMax ${ }^{\mathrm{TM}}$ Luminometer (Promega).

\section{Statistical analysis}

Results are presented as means \pm SD. Statistical analysis of PS exposure and SB staining as a function of time were performed using PRISM 8 software (GraphPad) using a two-way ANOVA with the Geisser-Greenhouse correction (matched values were stacked into a subcolumn). For the influx and efflux dataset, homogeneity of variances and data normality were checked graphically (boxplots, QQPlots, respectively). Analysis of the influx of Texas Red-labeled dextrans was done making use of a generalized linear model (GLM), Poisson family. To study the effect of dextran size on either the SB-negative (SB-) and SB-positive (SB+) cells, the factor variables doxycycline addition and measured point in time $(0,2,4,6,8$ and $10 \mathrm{~h}$ of anti-Fas treatment) and the discrete variable dextran size were included in the model. To study the effect of doxycycline on the influx of Texas Red-labeled dextrans, doxycycline addition, the measured point in time $(0,2,4,6,8$ and $10 \mathrm{~h}$ of anti-Fas treatment) and dextran size were all set as factor variables in the GLM. Multiple comparisons were made making use of the package "multcomp" [35].

To analyze the efflux of FITC-labeled dextrans, the dataset was split into three populations ( $\mathrm{SB}-, \mathrm{SB}$ low+, SB high+). For both datasets, a GLM (Gaussian family) was fitted to study the effect of dextran size and doxycycline on the efflux of dextrans. The factor variables doxycycline, measured point in time $(0,2,4,6,8$ and $10 \mathrm{~h}$ of anti-Fas treatment) and the discrete variable dextran size were included 
in the model. Again, multiple comparisons were made using the package "multcomp". All analyses were done in R, version 4.3 on three biological replicates of each data-set [36].

Differences with a $p$-value $<0.05$ were considered significant and indicated as followed: ns $=$ not significant; ${ }^{*} p<0.05 ; * * p<0.01 ; * * * p<0.001$.

\section{Results}

\section{Gasdermin E accelerates plasma membrane permeabilization during apoptosis-driven secondary necrosis as measured by SYTOX Blue-mediated nuclear staining.}

As conflicting findings were reported on the contribution of GSDME to apoptosis-driven secondary necrosis $[12,13$, $16,17]$, we decided to investigate the GSDME function in the murine fibrosarcoma cell line L929 stably expressing the human Fas receptor (L929sAhFas). Treatment of L929sAhFas cells with agonistic anti-human Fas antibodies induces apoptosis and caspase- 3 activation via the FADD/caspase8-dependent proteolytic pathway [2, 37-40]. As expected, treating L929sAhFas with anti-Fas resulted in the generation of a GSDME fragment of $\sim 35 \mathrm{kDa}$ (Fig. 1a), indicating proteolytic activation of GSDME by caspase- 3 as previously reported [12, 41]. To investigate the role of GSDME in anti-Fas-mediated apoptosis, we generated Gsdme knockout (KO) L929sAhFas clones by CRISPR/Cas9 gene editing (Fig. 1b). Next, we investigated whether the loss of GSDME expression in Gsdme KO L929sAhFas clones (KOcl1 and KOcl2) affected the kinetics of the uptake of the cell-impermeable DNA-binding fluorescent dye SB during apoptosisdriven secondary necrosis (Fig. 1c). Upon anti-Fas treatment, Gsdme KO L929sAhFas clones (KOcl1 and KOcl2) showed a delay in the uptake of SB compared to the parental cells and Gsdme wild-type (WT) clones in which CRISPR/ Cas9 gene-editing failed to interrupt Gsdme (WTcl1 and WTcl2, Fig. 1c), indicating delayed plasma membrane permeabilization in absence of GSDME expression, as concluded from the SB staining. To confirm that this delay was GSDME dependent and did not result from a clonal effect, Gsdme KOcl2 L929sAhFas was reconstituted with a doxycycline-inducible mGSDME construct using viral transduction, hereafter referred to as L929sAhFas iGSDME cells. Treatment of these cells with doxycycline resulted in the expression of GSDME that was cleaved to its active form upon treatment with anti-Fas (Fig. 1d). To compare the progression of apoptosis between GSDME-expressing (L929sAhFas iGSDME+) and GSDME-deficient (L929sAhFas iGSDME-) cells in more detail, we measured nuclear staining by SB and membrane surface PS exposure with Annexin V (AnnV) (Fig. 1e). Reconstitution of GSDME expression in L929sAhFas iGSDME cells by doxycycline treatment accelerated SB-positivity upon anti-Fas treatment compared to GSDME-deficient cells (Fig. 1e, f), suggesting that the plasma membrane permeabilization kinetics are slower in cells lacking GSDME. Interestingly, upon anti-Fas treatment, both L929sAhFas iGSDME+ and iGSDME- cells displayed a similar increase in membrane surface PS exposure, as measured by AnnV staining (AnnV+cells, Fig. 1g), and total apoptotic and secondary necrotic cell death combined (AnnV+/SB - and SB+cells, Fig. S1). Given this similar kinetics of AnnV-positivity, the slower SB-positivity in L929sAhFas iGSDME- cells correlates with a prolonged PS single-positive stage (AnnV+/SB-, Fig. 1h). The number of AnnV+/SB- cells starts to decline in L929sAhFas iGSDME+ conditions, $4 \mathrm{~h}$ after anti-Fas treatment, while in cells lacking GSDME a prolonged PS single-positive stage (AnnV+/SB-) can be observed (Fig. 1h). These data suggest that the initial progression of apoptotic signaling, leading to PS exposure, is not affected by GSDME expression, but GSDME is required to speed up plasma membrane permeabilization as measured by SB staining. Moreover, our results indicate that the loss of GSDME expression delays but does not prevent plasma membrane permeabilization thereby suggesting that other, GSDME-independent, plasma membrane permeabilization mechanisms exist during apoptosis-driven secondary necrosis in L929sAhFas cells.

\section{Gasdermin E pore formation supports influx of $10 \mathrm{kDa}$ dextrans independently of plasma membrane permeabilization kinetics}

Having confirmed that GSDME expression accelerates nuclear DNA staining by SB (Fig. 1f), we next evaluated whether GSDME-dependent membrane permeabilization supports the influx of large, membrane-impermeable macromolecules as well. Texas Red-labeled dextrans with a size of $10 \mathrm{kDa}$ (TR10) were used to this end, allowing convenient quantification of influx by flow cytometry (Fig. 2a). Texas Red signal was assessed in SB- and SB+cells separately, according to the zones indicated in Fig. 2b. Remarkably, treatment of L929sAhFas iGSDME cells with anti-Fas followed by incubation with TR10 and SB resulted in a TR10 single-positive population (Fig. 2b, TR10+/SB-, black arrow) and a double-positive population (Fig. 2b, TR10+/ $\mathrm{SB}+$ ), suggesting that TR10 can already enter the cells before SB stains the nuclear DNA (Fig. 2b). Unlike Fasinduced PS exposure, which happened independently of GSDME expression (Fig. 1g), TR10 tends to accumulate in twice as much SB- L929sAhFas iGSDME+ cells compared to SB- cells lacking GSDME (Fig. 2c). As the apoptotic phase and thus apoptotic blebbing and cellular fragmentation (SB- status) of L929sAhFas GSDME+ cells is limited compared to cells lacking GSDME (Fig. 1f), the TR+/ 
(a)

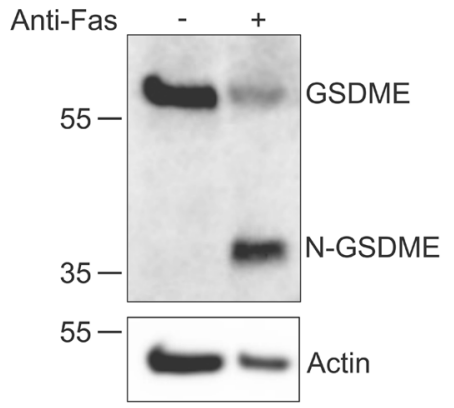

(d)

LsFas iGSDME

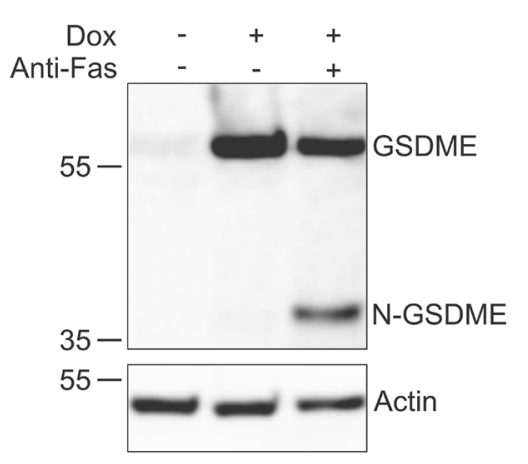

(f)

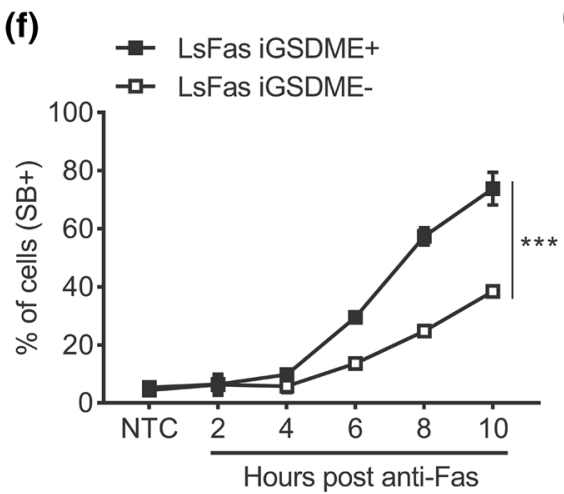

(e) (b)

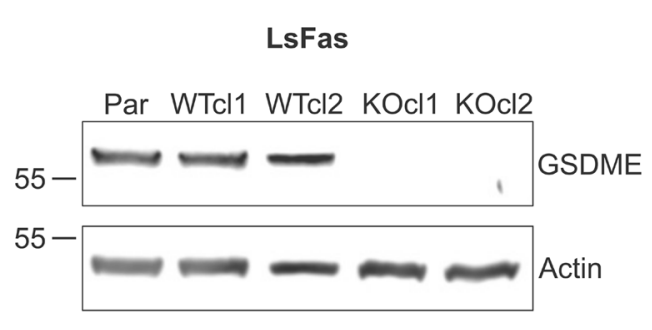

(c)

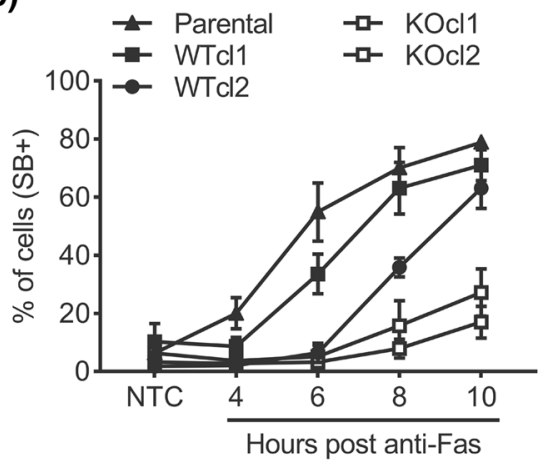

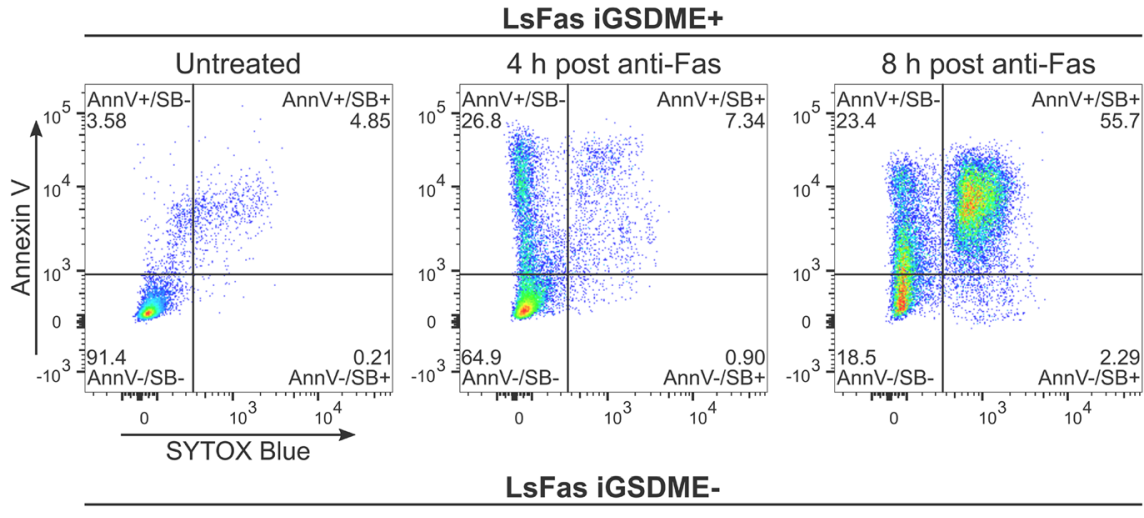

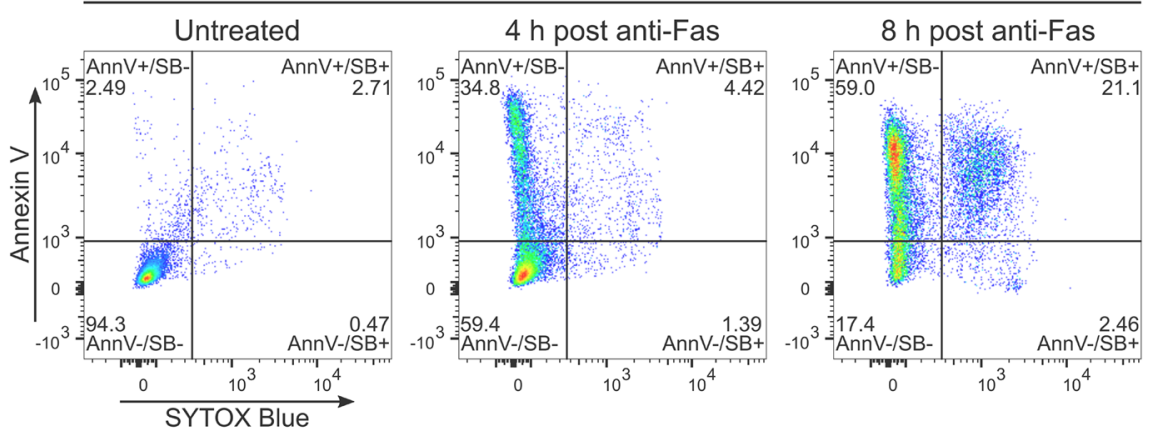

(g)

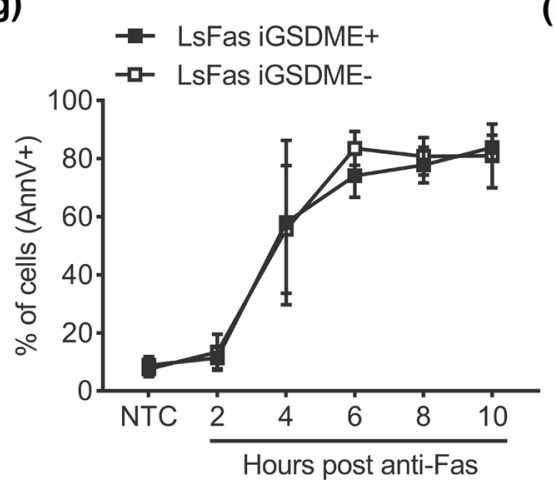

(h)

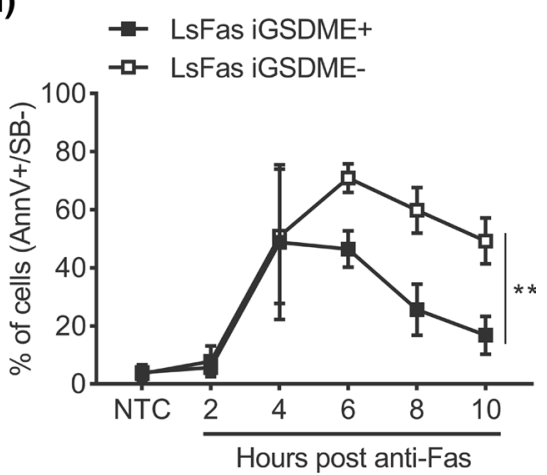

SB - events seen in the flow cytometry data are probably not resulting from nucleus-free cellular fragments. Instead, this observation suggests that the influx of TR10 is enhanced by GSDME-dependent plasma membrane permeabilization in the sublytic phase, before staining by SB. Noteworthy, the
$\mathrm{TR}+/ \mathrm{SB}-$ population seems relatively minor. As measurements were done every $2 \mathrm{~h}$ and GSDME-expressing cells proceed rapidly from the $\mathrm{TR}+/ \mathrm{SB}-$ to the $\mathrm{TR}+/ \mathrm{SB}+$ stage (Fig. 1f), we hypothesize that the time-interval between both stages is shorter than $2 \mathrm{~h}$ and thus explains the rather low 
४Fig. 1 Impact of GSDME expression on apoptosis-driven secondary necrosis in L929sAhFas cells. a Expression and proteolytic cleavage of GSDME in L929sAhFas upon anti-Fas treatment. b Expression of GSDME in different L929sAhFas clones upon CRISPR/Cas 9 gene editing. c Cell death kinetics of parental, Gsdme WT and KO L929sAhFas clones measured by SB staining via flow cytometry. d Expression of GSDME in L929sAhFas iGSDME cells upon doxycycline treatment. Subsequent treatment with agonistic anti-Fas antibodies promotes the generation of the active $35 \mathrm{kDa} \mathrm{N}$-terminal fragment (N-GSDME). e-h Flow cytometry analysis of L929sAhFas iGSDME cells with (L929sAhFas iGSDME+) or without (L929sAhFas iGSDME-) doxycycline-induced GSDME expression during apoptosis-driven secondary necrosis. e Representative flow cytometry dot plots after $4 \mathrm{~h}$ or $8 \mathrm{~h}$ treatment with anti-Fas. $\mathrm{f}$ Levels of secondary necrotic ( $\mathrm{SB}+)$ cells, $\mathbf{g}$ cells exposing PS (AnnV+) and $\mathbf{h}$ PS single-positive (AnnV+/SB-) cells in L929sAhFas iGSDME cells treated with anti-Fas. AnnV Annexin V; Dox doxycycline; GSDME, gasdermin E; KO knockout; LsFas L929sAhFas; NTC non-treatment control; Par parental; SB SYTOX Blue; WT wild-type

percentage of cells that resides in the TR10+/SB- singlepositive stage. However, we cannot rule out the possibility that only a minor subset of cells are stained by TR10 before SB staining while most cells are stained simultaneously with TR10 and SB. Consistent with the SB- population, the TR10+/SB+ population was higher in GSDME-expressing cells (Fig. 2d), which is expected as we showed that, upon anti-Fas treatment, staining by SB was accelerated in L929sAhFas iGSDME+ cells (Fig. 1f). Interestingly, we also observed a minor TR10-/SB+ population (Fig. 2b), pointing toward cells that become lytic with pores too small to allow the influx of TR10. It is conceivable that these cells died due to the massive presence of small pores, although this is just speculation and our experiment does not provide proof for this.

Next, we investigated whether the GSDME-related difference observed in TR10 influx is simply the result of delayed cell death kinetics, measured by SB staining, in L929sAhFas iGSDME- or a direct consequence of the absence of the GSDME pore itself. To neutralize the difference in cell death kinetics in our results, as pointed out in the previous section (Fig. 1f), we assessed TR10 uptake in the SB- and $\mathrm{SB}+$ population by normalizing the number of TR10- and TR10+ cells against the total number of cells in the respective populations (Fig. 2e, f). Apparently, the fraction of TR10 + cells upon anti-Fas treatment in SB- L929sAhFas iGSDME- cells was limited and significantly less compared to when GSDME was present (Fig. 2e). This suggests that GSDME pore formation itself allows the influx of TR10 before SB-mediated nuclear staining. In SB+cells, TR10 entered L929sAhFas iGSDME- cells much more easily, pointing to other permeabilization mechanisms taking place as well during apoptosis-driven secondary necrosis (Fig. 2f). Still, TR10 entered L929sAhFas iGSDME+ cells significantly more, indicating that plasma membrane permeabilization by GSDME enhances TR10 influx. Interestingly, both in SB- (Fig. 2e) and SB+cells (Fig. 2f), the fraction of TR10+cells increased over time. This suggests that the longer cells remain SB- upon anti-Fas treatment, the more cells get permeabilized, thereby promoting the entrance of TR10 while cells are in the sublytic phase and are not yet stained by SB. It also conceivable that more cells are permeabilized with the additional formation of larger pores allowing the entrance of TR10, as the molecular size sieving is determined by its largest pore. Though, we do not have hard experimental evidence for such consecutive small and large pore formation. Altogether, our results indicate that the presence of GSDME promotes a faster and increased influx of TR10 in both SB- and SB+ cells during apoptosis-driven secondary necrosis.

\section{Gasdermin E pore formation facilitates the influx of large dextrans in a size-dependent manner}

As TR10 is able to enter L929sAhFas iGSDME cells even when GSDME is absent, we wondered whether there is a molecular weight above which dextrans can no longer enter GSDME-deficient cells. Therefore, we examined the influx of Texas Red-labeled dextrans of $40 \mathrm{kDa}$ (TR40), $70 \mathrm{kDa}$ (TR70) and of $2000 \mathrm{kDa}$ (TR2000) and how this is affected by GSDME expression in L929sAhFas iGSDME cells upon anti-Fas treatment. Influx of Texas Red-labeled dextrans was again assessed in both $\mathrm{SB}-$ and $\mathrm{SB}+$ cells separately. Overall, upon $8 \mathrm{~h}$ (Fig. 3a) and $10 \mathrm{~h}$ (Fig. 3b) of treatment with anti-Fas, absence of GSDME expression significantly reduced the influx of all dextran sizes in SBL929sAhFas iGSDME cells, while influx clearly did happen when GSDME was present, except for TR2000. Although prolonged anti-Fas treatment promoted the influx of Texas Red-labeled dextrans up to $70 \mathrm{kDa}$ in both L929sAhFas iGSDME+ and iGSDME - cells, this was still significantly lower in absence of GSDME (Fig. 3b). Moreover, the uptake of Texas Red-labeled dextrans in SB- cells decreased with increasing dextran size, both in the absence $(10 \mathrm{~h}, p<0.01)$ and presence $(8 \mathrm{~h}, p<0.05 ; 10 \mathrm{~h}, p<0.01)$ of GSDME expression (Fig. 3a, b). These observations point toward pore formation during apoptosis-driven secondary necrosis with a rather variable instead of a fixed size. These results suggest that GSDME pores, formed in SB- L929sAhFas iGSDME cells, allow the passage of dextrans up to at least $70 \mathrm{kDa}$ while they exclude the entrance of Texas Red-labeled dextrans equal or larger than $2000 \mathrm{kDa}$. Importantly, note that the GSDME-dependent influx of Texas Red-labeled dextrans happened prior to SB staining, suggesting that GSDME membrane permeabilization during apoptosis-driven secondary necrosis does not occur concurrently with nuclear DNA staining by small SB molecules $(0.4 \mathrm{kDa})$ and already happens prior to secondary necrosis. 
(a)

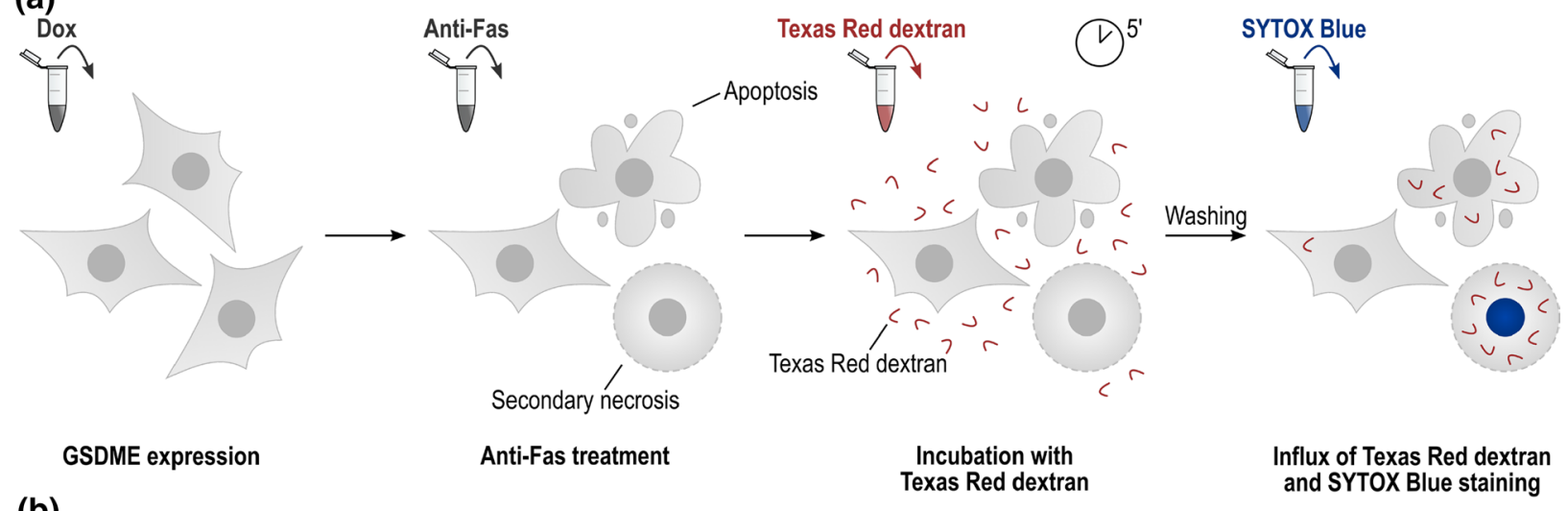

(b)

\section{LsFas iGSDME+}

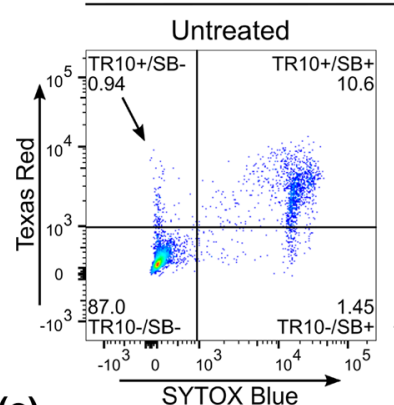

(c)

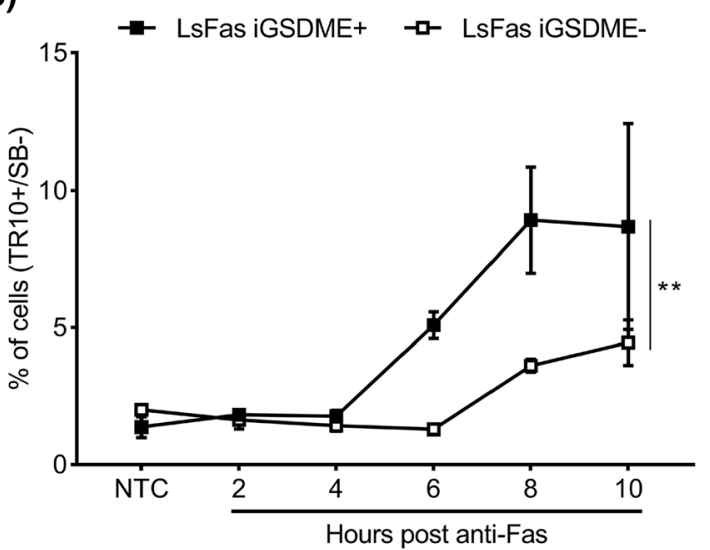

(e)

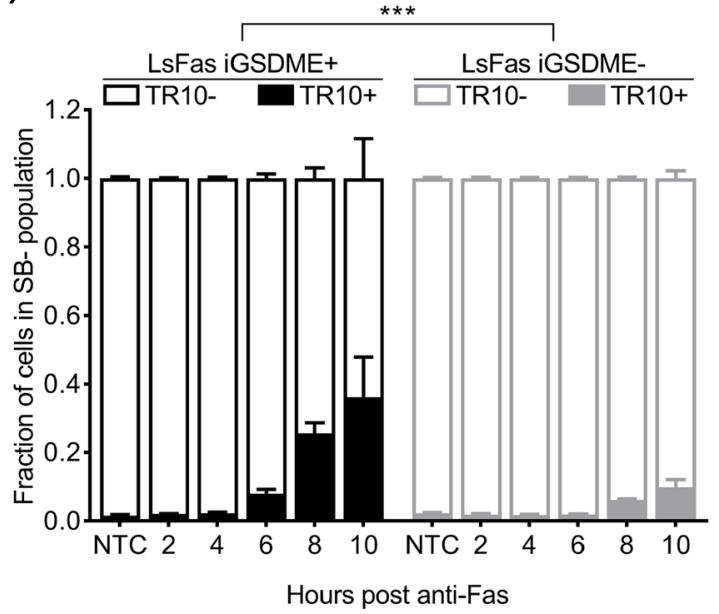

LsFas iGSDME-

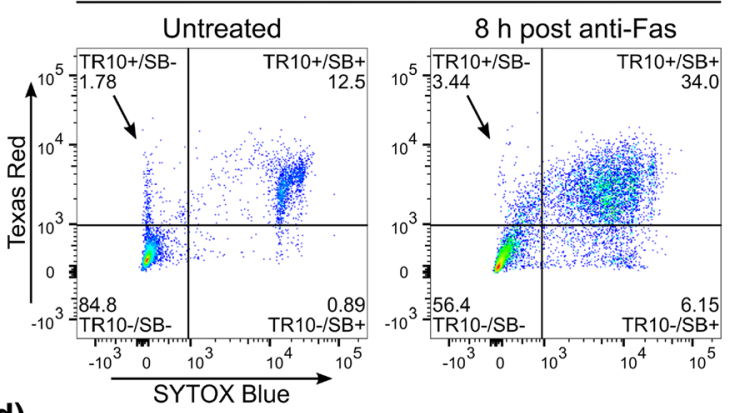

(d)

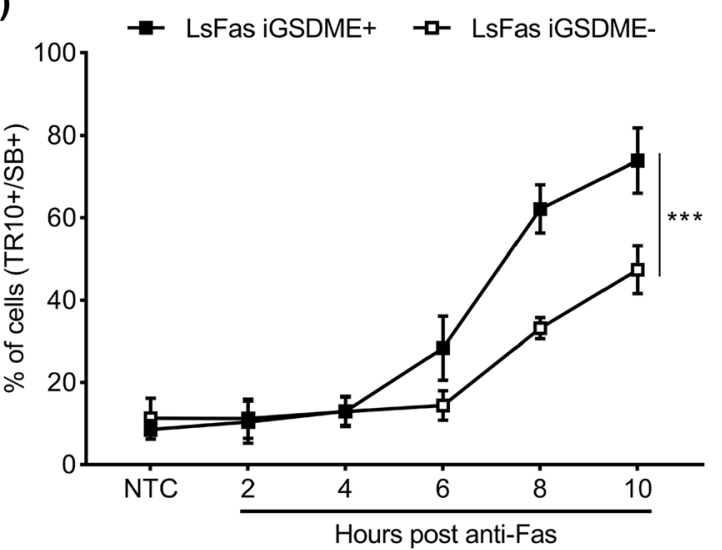

(f)

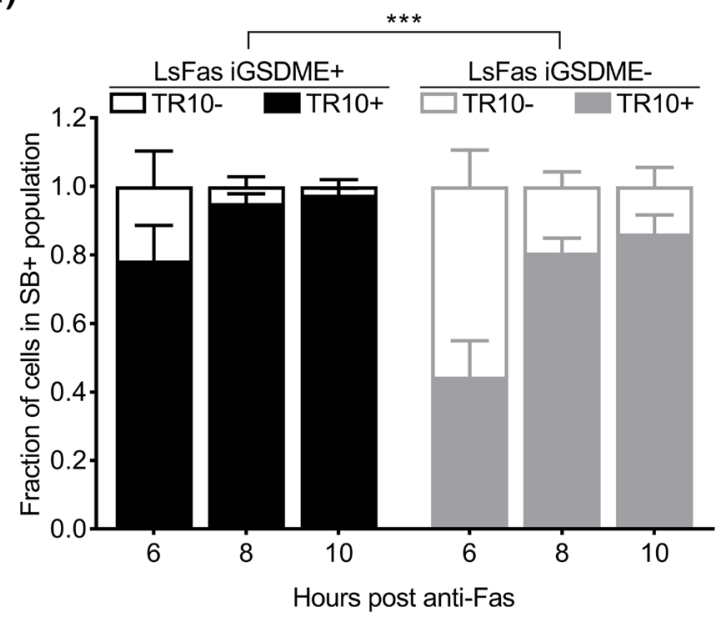


4Fig. 2 Monitoring of Texas Red-labeled dextran $10 \mathrm{kDa}$ (TR10) influx in L929sAhFas iGSDME cells during apoptosis-driven secondary necrosis. a Principle of Texas Red-labeled dextran staining of L929sAhFas iGSDME cells. b-f Flow cytometry analysis of L929sAhFas iGSDME cells with (L929sAhFas iGSDME+) and without (L929sAhFas iGSDME-) doxycycline-induced GSDME expression during apoptosis-driven secondary necrosis. b Representative plots of L929sAhFas iGSDME cells untreated and after treatment with anti-Fas for $8 \mathrm{~h}$. c Levels of Texas Red single-positive cells (TR10+/SB-) in L929sAhFas iGSDME cells upon anti-Fas treatment. d Levels of Texas Red and SB double-positive (TR10+/ $\mathrm{SB}+$ ) cells in L929sAhFas iGSDME cells upon anti-Fas treatment. e Fraction of Texas Red positive (TR10+) and Texas Red negative (TR10-) cells in the SB- population. f Fraction of Texas Red positive (TR10+) and Texas Red negative (TR10-) cells in SB+population. Dox doxycycline; GSDME gasdermin E; LsFas L929sAhFas; SB SYTOX Blue; NTC non-treatment control; TR Texas Red

The GSDME dependency for the influx in SB+L929sAhFas iGSDME cells was less pronounced for TR10 after treatment with anti-Fas for $8 \mathrm{~h}$ (Fig. 3c), whereas after $10 \mathrm{~h}$ influx of sizes 10-70 kDa revealed to be not significant between L929sAhFas iGSDME+ and iGSDME- cells (Fig. 3d). Nevertheless, GSDME expression clearly promoted the entrance of TR2000 in SB+L929sAhFas iGSDME+ cells after treatment with anti-Fas for $10 \mathrm{~h}$ (Fig. 3d). Although this suggests that GSDME pores in $\mathrm{SB}+$ cells might even favor the entrance of molecules up to $2000 \mathrm{kDa}$, most of the cells $(\sim 70 \%)$ were still negative for TR2000. Furthermore, similar to the influx in SB- cells, influx of Texas Red-labeled dextrans significantly decreased with increasing dextran size. On average, dextran size had an overall statistical significant effect on the influx $8 \mathrm{~h}$ after anti-Fas treatment in L929sAhFas iGSDME- cells (Fig. 3c, $p<0.001$ ) and $10 \mathrm{~h}$ after anti-Fas treatment in L929sAhFas iGSDME+ (Fig. 3d, $p<0.05$ ) and iGSDME- (Fig. 3d, $p<0.001$ ) cells. Linear fit of the data points for TR10, TR40 and TR70 upon $8 \mathrm{~h}$ (Fig. 3e) and $10 \mathrm{~h}$ (Fig. 3f) of anti-Fas treatment, allowed us to interpolate the size of molecules that can enter $50 \%$ of the cells (Fig. 3e, f). According to our calculations, GSDME expression would allow the uptake of molecules between $115(8 \mathrm{~h})$ and $125 \mathrm{kDa}(10 \mathrm{~h})$ in $50 \%$ of the SB + L929sAhFas iGSDME + cells, while the absence of GSDME limits the molecular size to $53(8 \mathrm{~h})$ and $87 \mathrm{kDa}(10 \mathrm{~h})$.

\section{Nanoparticle-sensitized photoporation constitutes a suitable method for introducing dextrans into cells without influencing apoptosis kinetics}

Although monitoring the influx of Texas Red-labeled dextrans provided insight into the molecular weight of molecules that can enter during apoptosis-driven secondary necrosis, we aimed to evaluate whether the same conclusions are reached when monitoring the efflux of macromolecules. Monitoring efflux should better reflect the physiological situation where intracellular content like Damage Associated
Molecular Patterns (DAMPs) or even cell organelles are released from dying cells. Instead of Texas Red-labeled dextrans, of which we observed that they tend to interact with intracellular constituents, we used FITC-labeled dextrans, which are inert in cells [42]. For delivery of FITClabeled dextrans in the cytosol of L929sAhFas cells, we used nanoparticle-sensitized photoporation as an emerging intracellular delivery technique that minimally perturbs the cellular homeostasis (Fig. 4a) [23, 24, 27]. L929sAhFas cells were first incubated with cationic AuNPs, which attach to the plasma membrane. After washing away unbound AuNPs, cells were irradiated with a $5 \mathrm{~ns}$ laser pulse $(\lambda=532 \mathrm{~nm}$, $0.86 \mathrm{~J} / \mathrm{cm}^{2}$ ), resulting in the formation of transient pores in the plasma membrane through which the fluorescently labeled dextrans can diffuse into the cytosol.

First, we optimized the AuNP concentration as a function of delivery efficiency and cell metabolic activity. To maximize cell loading and minimize potential cell cytotoxicity by photoporation, different AuNP concentrations (2, 4, 6, 8 and $16 \times 10^{7} \mathrm{AuNPs} / \mathrm{mL}$ ) were screened using a fixed laser pulse fluence of $0.86 \mathrm{~J} / \mathrm{cm}^{2}$. We observed an increase in the percentage of cells positive for FITC-labeled dextrans of $10 \mathrm{kDa}$ (FD10) (Fig. S2a), as measured by flow cytometry, and a decrease in metabolic activity, as measured with the CellTiter-Glo® assay (Fig. S2b), for increasing AuNP concentrations. Allowing a 30\% reduction in metabolic activity, determined by the ATP content of live cells, the optimal AuNP concentration was set at $6 \times 10^{7}$ AuNPs/ml for all further experiments, in which case near $100 \%$ of the cells are FD10 positive. In addition, we tested whether photoporation of FD10 influenced cell death kinetics of L929sAhFas cells when treated with anti-Fas. Gsdme WT and KOcl2 L929sAhFas cells were photoporated in the presence of FD10 and cell death kinetics, as determined by SB staining, was compared with untreated control cells. Cell death kinetic measurements of photoporated cells remained unchanged compared to the untreated control cells (Fig. S3). Based on these results, we concluded that photoporation can efficiently deliver FITC-labeled dextrans in L929sAhFas cells without influencing anti-Fas-mediated apoptosis-driven secondary necrosis.

\section{Efflux of dextrans of $10 \mathrm{kDa}$ occurs independently of gasdermin E expression and cell death kinetics during apoptosis-driven secondary necrosis}

Having optimized the cytosolic delivery of FD10 with nanoparticle-sensitized photoporation, we investigated the efflux of the dextrans from L929sAhFas iGSDME cells upon anti-Fas treatment, as a function of the SB signal of the cells (Fig. 4a). Following this strategy, we gated the whole cell population undergoing anti-Fas treatment into: no SB signal (SB-), a low SB signal (SB low+) and a high SB signal 

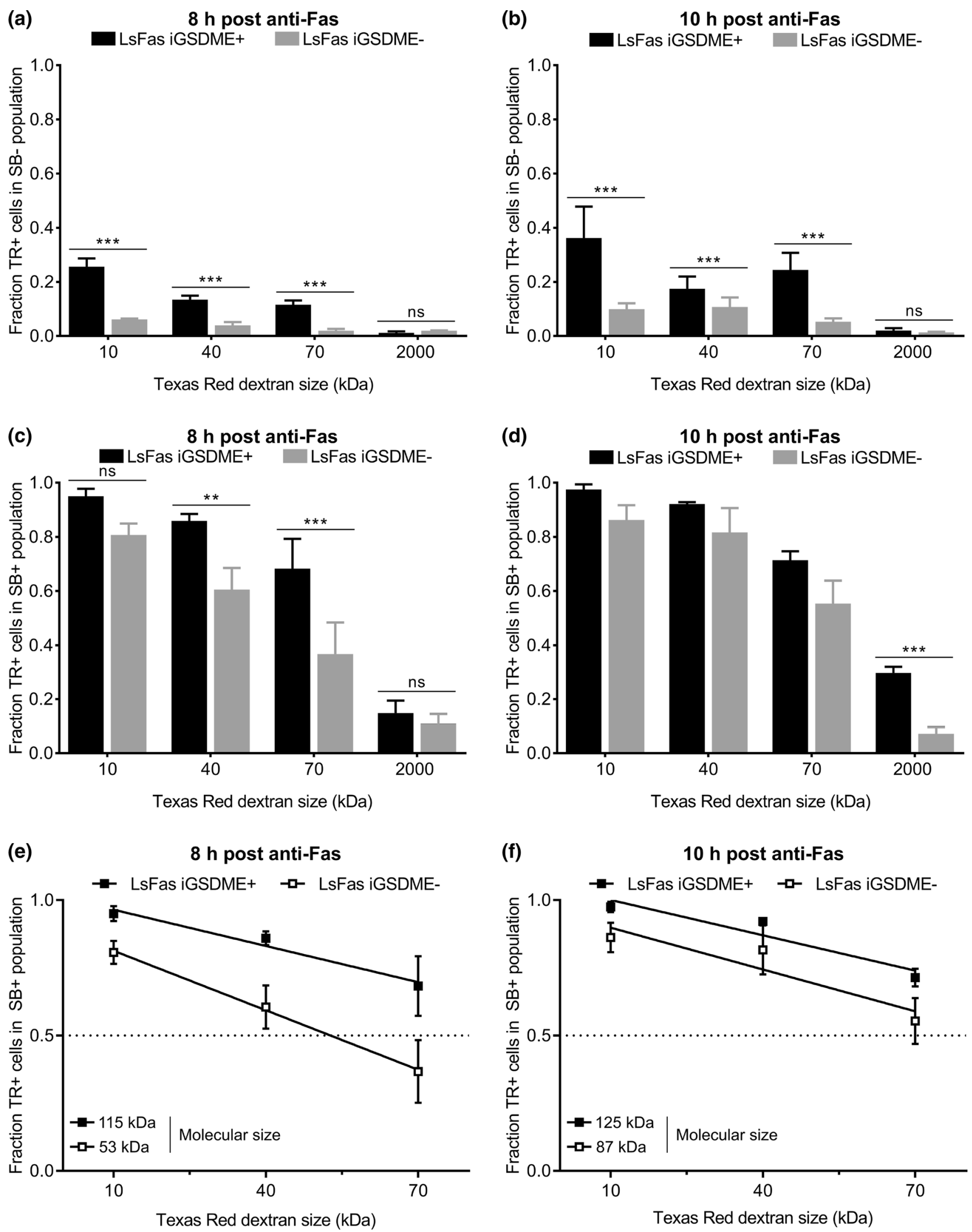
4Fig. 3 Influx of Texas Red-labeled dextrans of $10 \mathrm{kDa}$ (TR10), $40 \mathrm{kDa}$ (TR40), $70 \mathrm{kDa}$ (TR70) and $2000 \mathrm{kDa}$ (TR2000) in L929sAhFas iGSDME during apoptosis-driven secondary necrosis. a-f Flow cytometry analysis of Texas Red-labeled dextran uptake in L929sAhFas iGSDME cells with (L929sAhFas iGSDME+) and without (L929sAhFas iGSDME-) doxycycline-induced GSDME expression after $8 \mathrm{~h}$ and $10 \mathrm{~h}$ treatment with anti-Fas. a, b Fraction of the SB- population that is positive for various sizes of Texas Redlabeled dextrans. c, d Fraction of the SB+population that is positive for various sizes of Texas Red-labeled dextrans. e, $\mathbf{f}$ Linear fit of data points for the fractions of the SB+population positive for TR10, TR40 and TR70. Intersection of this line with the dotted line provides a rough estimation of molecular sizes that can enter $50 \%$ of the $\mathrm{SB}+$ population. LsFas L929sAhFas; SB SYTOX Blue; TR Texas Red

(SB high+) (Fig. 4b). Flow cytometry data revealed that both in the presence and absence of GSDME, FD10 was released from the cells when they became positive for the SB-mediated nuclear staining (Fig. 4b, c). Interestingly, a bimodal distribution in the FITC signal was observed in cells with a low SB signal (Fig. 4c, middle panel), which was not observed in the influx experiments. This observation indicates that in the initial stage, when the nucleus of cells gets stained by SB, a part of those cells had already lost FD10 content while the other part was still clearly FD10 positive. In contrast, only a very few SB- cells were negative for FD10 (Fig. 4c, left panel), while cells with a high SB+ signal had practically all lost their dextran content (Fig. 4c, right panel). Of note, these results were observed independently of GSDME expression.

This strong heterogeneity of dextran release between $\mathrm{SB}-$ and SB high+ cells is confirmed when plotting the mean fluorescence intensity (MFI) of FD10 in the SB-, $\mathrm{SB}$ low+ and SB high+ population, respectively, relative to the untreated SB-population. This normalization is also referred to as the relative mean fluorescence intensity (rMFI) (Fig. 4d-f). Note that we chose to use the rMFI to present the loss of FITC-labeled dextrans, since photoporation delivery efficiency (i.e. the percentage of FD10 positive cells) decreases with increasing dextran size [24, 34]. Furthermore, normalization of the MFI relative to the untreated SB- population allows for easy comparison of the efflux of different sizes of FITC-labeled dextrans as relative differences in dextran delivery after photoporation are taken into account. Only a minimal amount of FD10 content was released from SB- cells (Fig. 4d). Surprisingly, the rMFI decreased slightly but significantly more in the absence of GSDME than in GSDME-reconstituted cells, suggesting that there would be more content release over time in $\mathrm{SB}-$ cells when GSDME is lost. This is a counterintuitive result, which is in contrast with our influx data that pointed toward facilitated uptake of dextrans when GSDME pores are formed in $\mathrm{SB}-$ cells. However, referring to the prolonged stage of PS-positivity in SB- cells without GSDME expression (Fig. 1h), we hypothesize that the larger drop in rMFI in those cells can be attributed to the prolonged release of FD10-loaded apoptotic membrane blebs in cells lacking GSDME. Taken together, based on these data, we could not claim that GSDME expression facilitates the efflux of small dextrans in SB- L929sAhFas iGSDME cells upon anti-Fas treatment.

In strong contrast to the SB- population, SB high+cells have lost almost all of their FD10 content irrespective of GSDME expression (Fig. 4f). While the SB low+ population had an intermediate rMFI level, being the result of a FD10-positive and-negative population, there was no difference between GSDME-expressing and non-expressing cells (Fig. 4e). Interestingly, treating cells for longer time periods with anti-Fas resulted in a decreased rMFI of FD10 in the SB low+ population (Fig. 4e). These observations would indicate that slower-dying cells, which enter the SB low+ stage at later time points, have a stronger tendency to release more content early-on in the dying process (SB low+ stage) before attaining a full SB signal, while the opposite would be the case for faster-dying cells, which are stained by SB shortly after anti-Fas treatment. A possible explanation for this would be that slower-dying cells would eventually become more permeabilized during the sublytic phase than faster-dying cells, which progress more rapidly toward the SB low+ stage.

\section{Efflux of dextrans is size dependent but gasdermin E independent during apoptosis-driven secondary necrosis}

To evaluate whether the release of dextrans from anti-Fastreated L929sAhFas iGSDME cells is size dependent, we monitored the efflux of FITC-labeled dextrans of increasing molecular weights: $4 \mathrm{kDa}$ (FD4), $40 \mathrm{kDa}$ (FD40), $70 \mathrm{kDa}$ (FD70), $150 \mathrm{kDa}$ (FD150), $250 \mathrm{kDa}$ (FD250), $500 \mathrm{kDa}$ (FD500) and $2000 \mathrm{kDa}$ (FD2000). Efflux in SB- cells was size independent, albeit that L929sAhFas iGSDME- cells had lost more FITC-labeled dextrans compared to L929sAhFas iGSDME+ cells (Fig. 5a). This supports our previous hypothesis that dextran loss is dominated by blebbing in SBcells, especially in the absence of GSDME. In contrast, SB high + cells have lost almost all FITC-labeled dextran content of all sizes independently of GSDME expression (Fig. 5c). Nevertheless, a slight size-dependent trend was seen, indicating less dextran release with increasing molecular weight, which was significant in the absence of GSDME expression (Fig. 5c). This size-dependent trend was more obvious in SB low + cells (Fig. 5b), although again only significant for GSDME-deficient cells. Together these data point toward a size-dependent but GSDME-independent release of dextrans as soon as cells start to become positive for SB. Although no clear size cut-off of the GSDME pore could be determined via this strategy, release of FITC-labeled dextrans, 
(a)

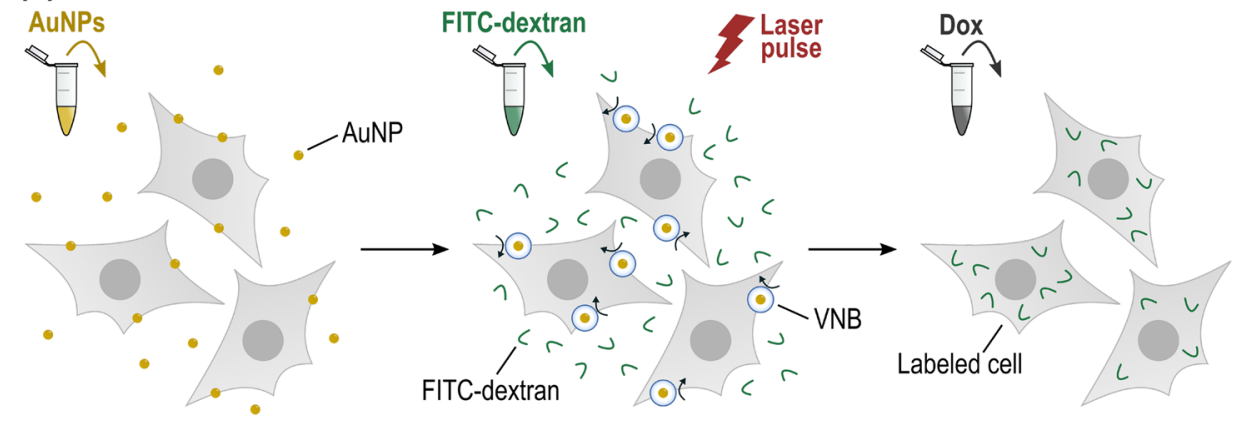

Nanoparticle adsorption
GSDME expression
Pulsed laser irradiation and cytosolic delivery

(b)

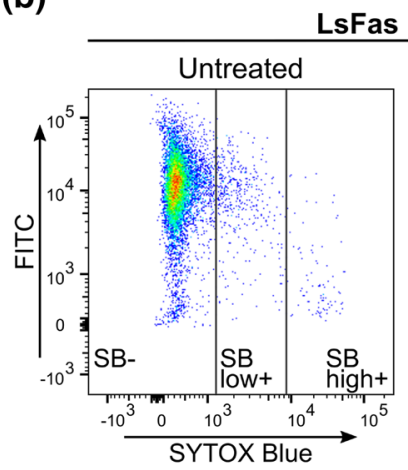

LsFas iGSDME+

(c)

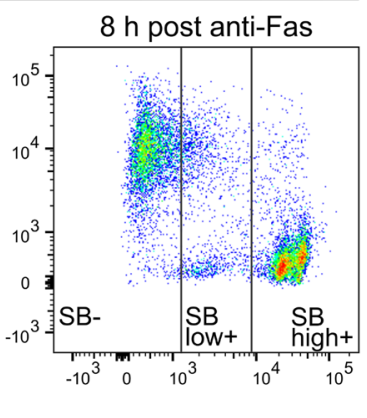

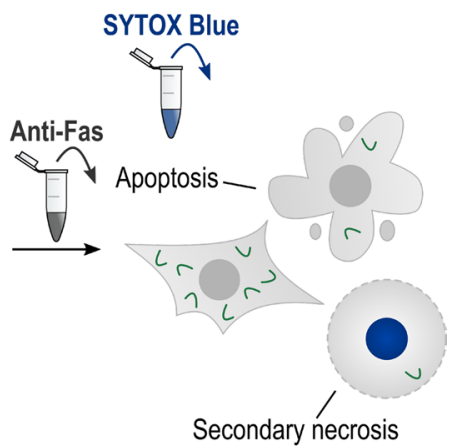

Efflux of loaded FITC-dextran and SYTOX Blue staining

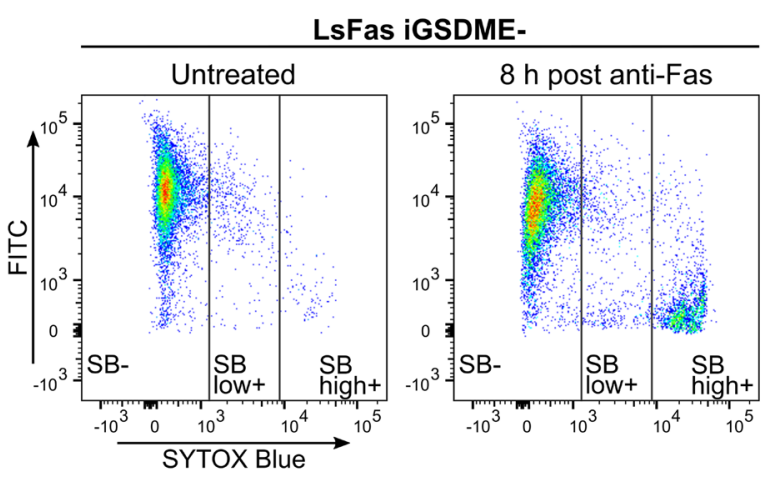

SB-

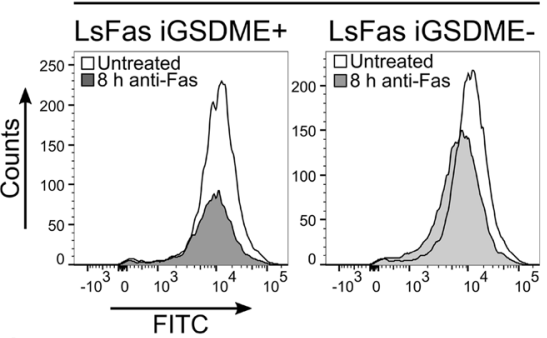

(d)
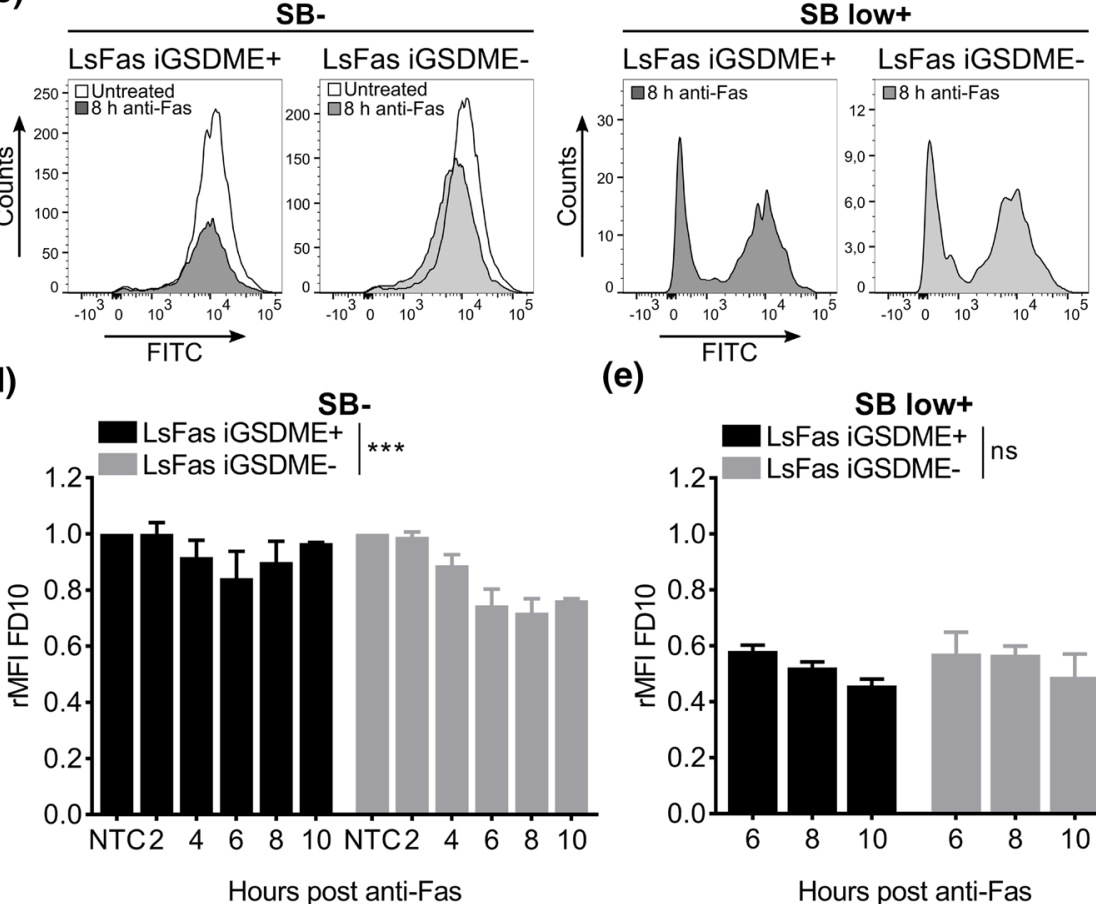

(e)

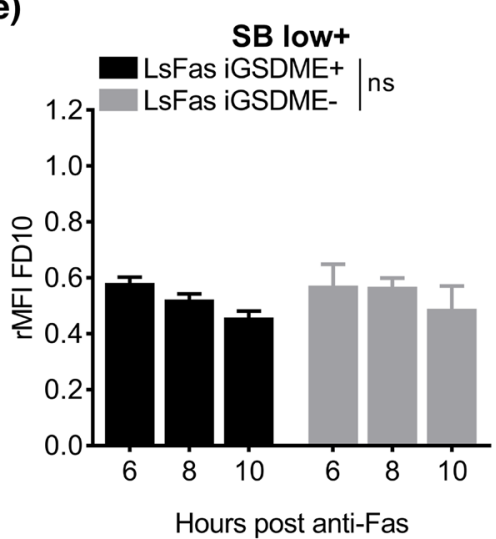

SB high+

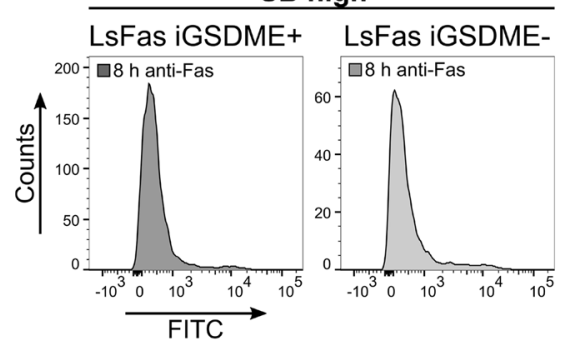

(f)

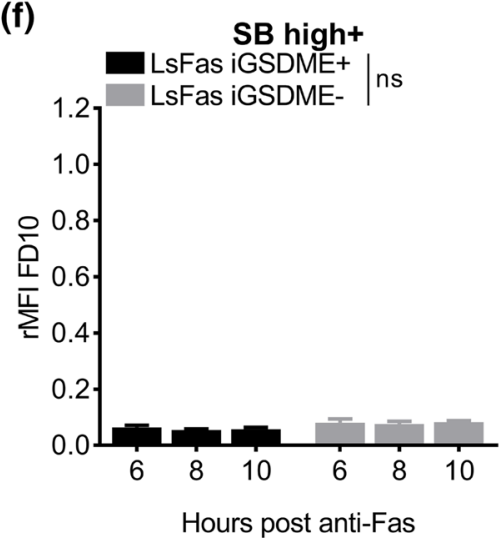

in general, is size dependent during apoptosis-driven secondary necrosis. This can be concluded from the stronger release of smaller-sized dextrans in SB low+cells compared to larger-sized dextrans, which tend to be released rather at the end of permeabilization (Fig. 5a, b, Fig. S4a, b). The fact that larger-sized dextrans are less easily released as compared to smaller-sized dextrans may indicate the presence of another, GSDME-independent, plasma membrane permeabilization subroutine in $\mathrm{SB}+$ cells that allows the release of FITC-labeled dextrans in a size-dependent way. Of note, 
4Fig. 4 Efflux of FITC-labeled dextrans $10 \mathrm{kDa}$ (FD10) from L929sAhFas iGSDME cells during apoptosis-driven secondary necrosis. a Principle of monitoring efflux of FITC-labeled dextrans after photoporation-based dextran loading. b-f Flow cytometry analysis of FD10 release in L929sAhFas iGSDME with (L929sAhFas iGSDME+) and without (L929sAhFas iGSDME-) doxycyclineinduced GSDME expression when treated with anti-Fas. b Scatter plots of L929sAhFas iGSDME in presence (left) and absence (right) of GSDME expression untreated and after $8 \mathrm{~h}$ treatment with antiFas. c Histogram plots representing the distribution of the FD10 signal in the three zones of SB staining: SB- (left), SB low+ (middle) and SB high+(right). d Graph representing the relative mean fluorescence intensity (rMFI) of FD10 in the SB-population (relative to the untreated SB-population) as a function of anti-Fas treatment. $\mathbf{e}$ Graph representing the relative mean fluorescence intensity (rMFI) of FD10 in the SB low+ population (relative to the untreated SB- population) as a function of anti-Fas treatment. $\mathbf{f}$ Graph representing the relative mean fluorescence intensity (rMFI) of the SB high+population (relative to the untreated SB- population) as a function of anti-Fas treatment. $A u N P$, gold nanoparticle; Dox doxycycline; FD FITC-dextran; GSDME gasdermin E; LsFas L929sAhFas; NTC nontreatment control; $S B$ SYTOX Blue; $V N B$ vapor nanobubble

as limited efflux was observed in $\mathrm{SB}-$ cells, the subroutine promoting efflux of FITC-labeled dextrans coincided with SB staining in our cells. Importantly, as concluded from previous sections, cell death kinetics measured by SB-mediated nuclear staining is delayed in L929sAhFas iGSDME cells in the absence of GSDME expression (Fig. 1f). Therefore, one can expect that a delayed efflux of FITC-labeled dextrans is similar to the delay of influx (not corrected for cell death kinetics) in L929sAhFas iGSDME cells in absence of GSDME expression (Fig. 2c, d). Indeed, when evaluating the rMFI (relative to the total untreated cell population) of the total cell population (without gating for SB signal), overall a slower efflux of FITC-labeled dextrans was observed in L929sAhFas iGSDME- cells as a function of anti-Fas treatment (Fig. 5d). Although efflux of FITC-labeled dextrans through the GSDME pore seems unlikely, this observation highlights the importance of GSDME in the overall cellular release of FITC-labeled dextrans. Altogether, our results suggest that GSDME contributes to a larger set of mechanisms steering membrane permeabilization during apoptosis-driven secondary necrosis and by consequence content release.

\section{Discussion}

Plasma membrane permeabilization following apoptosisdriven secondary necrosis has always been perceived as a non-regulated process of apoptotic cells in the absence of sufficient phagocytic cell capacity [2, 43]. Recently, it was shown that this plasma membrane permeabilization is a regulated process driven by caspase-3-mediated activation of GSDME [12]. This finding indicates that the cell can accelerate the process of permeabilization by engaging
GSDME-mediated release of intracellular content, which affects the inflammatory response [44]. Although pore formation by GSDMA3 and GSDMD has already been extensively studied [19, 21, 22], the kinetics and size characteristics of GSDME pore formation during apoptosis-driven secondary necrosis are currently unknown. Determining the degree of membrane permeabilization and identifying molecular sizes able to pass the plasma membrane upon GSDME expression may give insights into the membrane destabilizing behavior of GSDME and its role in progressing apoptotic cells toward secondary necrosis.

In the first part of this study, we showed that GSDME expression contributes to apoptosis-driven secondary necrosis in L929sAhFas cells by accelerating cell death kinetics measured by SB staining. This is consistent with the findings of Rogers et al. [12] stating that GSDME is necessary for the quick progression of apoptotic cells toward secondary necrosis. Additionally, we demonstrated that GSDME expression is dispensable for Fas-induced PS exposure in L929sAhFas, which is an early subroutine of apoptosis. As GSDME expression does accelerate plasma membrane permeabilization, dying cells remain longer in the PS singlepositive stage in the absence of GSDME expression. The physiological consequences of how the absence or presence of GSDME determines the lytic phase of the cell death resulting in a prolonged or shortened PS single-positive stage during which cellular content is contained, are currently unknown. It is tempting to speculate that prolonged exposure of eat-me signals on intact cell membranes in the absence of GSDME expression facilitates 'silent' clearance of these cells as phagocytes that engulf intact apoptotic cells secrete anti-inflammatory cytokines such as TGF $\beta$ and IL-10 while simultaneously suppressing pro-inflammatory cytokines [1, 45-47]. In contrast, DAMP release from perforated necrotic cells attract pro-inflammatory immune cells such as macrophages and neutrophils that release proinflammatory cytokines $[4,5,48]$. As such, GSDME expression was shown to increase phagocytosis of tumor cells by macrophages as well as the number and cytolytic activity of tumor-infiltrating natural-killer and CD8+T lymphocytes, resulting in reduced tumor growth [44].

In the second part of this study, we monitored the influx and efflux of dextran molecules of various sizes in L929sAhFas iGSDME cells with and without GSDME expression. Our results based on the influx of Texas Red-labeled dextrans suggest that GSDME-dependent pore-formation in the sublytic phase, before SB-mediated nuclear staining, allows the passage of molecules with sizes up to $70 \mathrm{kDa}$, while influx is reduced and delayed in the absence of GSDME expression. This is consistent with earlier reports presenting that GSDMD and GSDME pores in sublytic cells upon pyroptotic stimuli are crucial for the release of cytokines such as active IL-1 $\beta$ (18 kDa) [49-51]. Additionally, our 

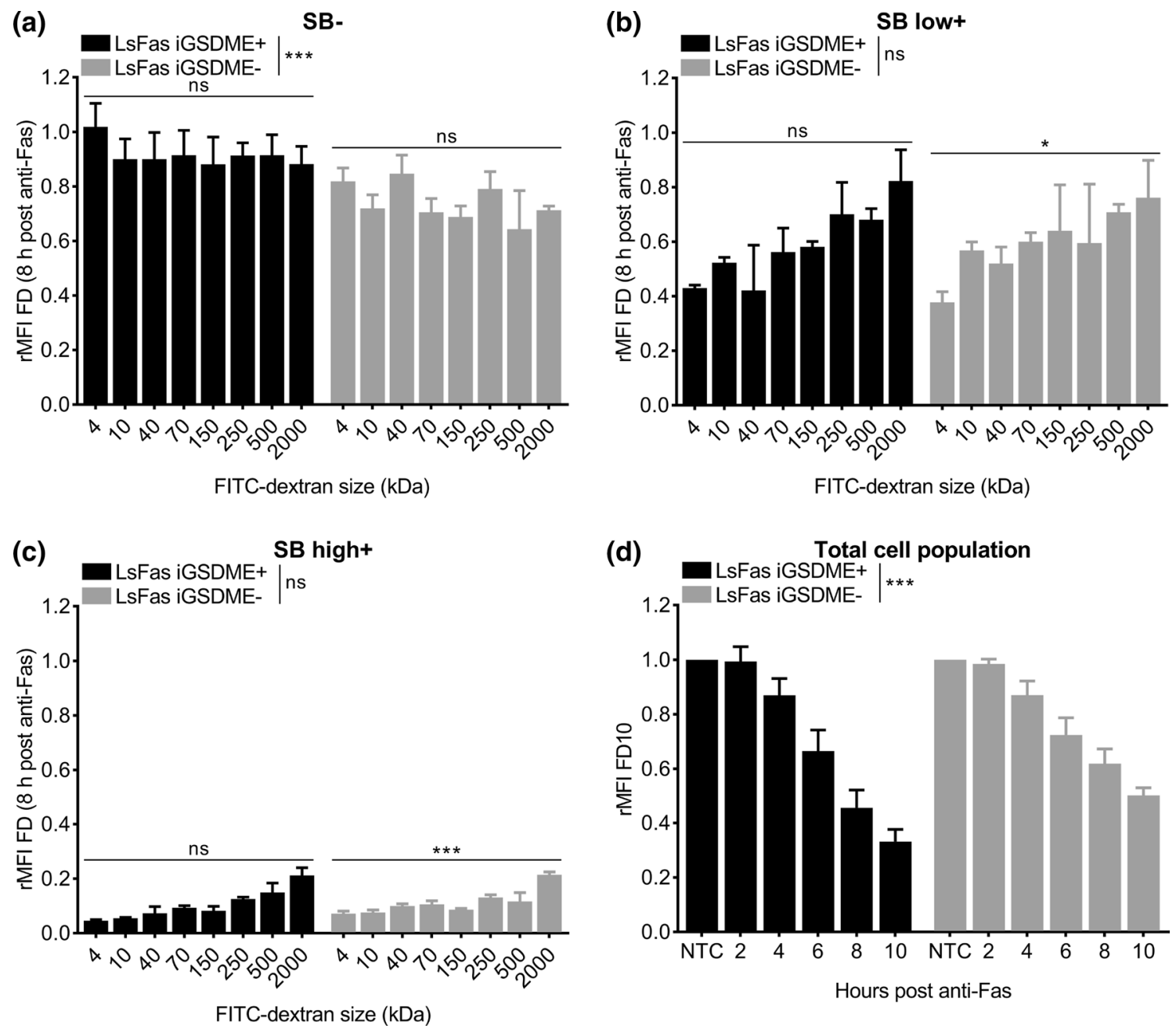

Fig. 5 Efflux of FITC-labeled dextrans of different sizes from L929sAhFas iGSDME cells during apoptosis-driven secondary necrosis. a-d Flow cytometry analysis of FITC-labeled dextran release in L929sAhFas iGSDME cells with (L929sAhFas iGSDME+) and without (L929sAhFas iGSDME-) doxycycline-induced GSDME expression upon treatment with anti-Fas. a-c Graphs representing the relative mean fluorescence intensity (rMFI, relative to

the untreated SB- population) for increasing sizes of FITC-labeled dextrans $\mathbf{a}$ in the SB-population, $\mathbf{b}$ in the SB low+ population and $\mathbf{c}$ in the SB high+population after $8 \mathrm{~h}$ treatment with anti-Fas. d Graph representing the relative mean fluorescence intensity (rMFI) of the total cell population (relative to the total untreated cell population) as a function of anti-Fas treatment. FD FITC-labeled dextran, LsFas L929sAhFas, NTC non-treatment control

influx-based results imply that GSDME also facilitates the uptake of larger dextrans in SB+cells, which possibly elucidates the contribution of GSDME to final cell lysis. From our influx experiments, we could estimate that GSDMEdriven plasma membrane permeabilization favors the passage of molecules up until $\sim 125 \mathrm{kDa}$. This is consistent with Evavold et al. [49] reporting that macromolecules such as lactate dehydrogenase $(144 \mathrm{kDa})$ were unable to pass GSDMD pores and were only released after complete cell lysis. Although our results based on the influx of dextrans allowed us to conclude that GSDME favors the entrance of macromolecules, a clear cut-off size for molecules able to pass GSDME pores was not observed since we report a decrease in the uptake of Texas Red-labeled dextrans with

increasing sizes. These observations might suggest that at any moment during cell death, permeabilization of plasma membranes may involve pores of different sizes that are simultaneously present in the cell population referring to the presence of alternative pore-forming molecules or less controlled pore-formation by GSDME. However, the formation of GSDME membrane pores of different sizes only seems plausible in the case of a plasma membrane-destabilizing mechanism such as the carpet-like model or the formation of toroid-like pores since oligomerization and formation of discrete $\beta$-barrel-shaped pores are dependent on thermodynamic stability. Nevertheless, the presence of different pore sizes could indicate that intermediate pores are formed that 
undergo a growing process until they reach their final stable form as shown for GSDMD pores [21, 22].

While influx experiments provided us with valuable insights regarding membrane permeabilization during apoptosis-driven secondary necrosis, we were keen to investigate the effect of this process on the efflux of FITC-labeled dextrans. Monitoring efflux should better reflect the physiological situation where intracellular content is released from dying cells. Interestingly, more intermediate dextran sizes are available with the FITC fluorophore, which could aid in drawing more precise conclusions about GSDME. We used nanoparticle-sensitized photoporation as an efficient intracellular delivery technique, of which we could show that it does not interfere with apoptosis kinetics. However, upon triggering of apoptosis-driven secondary necrosis, we did not find a contribution of GSDME to the efflux of FITClabeled dextrans from L929sAhFas iGSDME cells. In addition, SB high+ cells released almost all FITC-labeled dextrans while in our influx experiments, TR2000 failed to enter in most of the SB+cells. These observations suggest that other, GSDME-independent, subroutines exist that allow the release of FITC-labeled dextrans. The existence of different subroutines supporting membrane permeabilization during cell death has recently been shown by Kayagaki et al. They report that the cell-surface protein nerve injury-induced protein 1 (NINJ1) contributes to plasma membrane permeabilization during apoptosis-driven secondary necrosis, pyroptosis and necroptosis next to GSDME, GSDMD and mixed lineage kinase domain-like (MLKL) [52]. Which subroutine is responsible for the efflux of FITC-labeled dextrans in our system remains elusive, but similar to the influx of Texas Red-labeled dextrans, efflux of FITC-labeled dextrans occurs in a size-dependent manner. As to why GSDME pores seem to exclude FITC-labeled dextrans, we cannot rule out an electrostatic effect. FITC-labeled dextrans are anionic while Texas Red-labeled dextrans are more neutral. Recently, the GSDMD pore was shown to be predominantly negatively charged preventing the passage of negatively charged cargos [20].

\section{Conclusions}

We developed two strategies to elucidate the influence of GSDME in apoptosis-driven secondary necrosis and gained insights into the pore-forming and membrane permeabilizing behavior during this process. While a size dependency was observed for both influx and efflux of fluorescently labeled dextrans, we could only attribute an altered influx pattern to GSDME presence. Altogether, our results point to the existence of different subroutines that simultaneously regulate the passage of compounds during the cellular permeabilization process during apoptosis-driven secondary necrosis.

Supplementary Information The online version contains supplementary material available at https://doi.org/10.1007/s00018-021-04078-0.

Acknowledgements Research in the Vandenabeele group is supported by Flemish grants (EOS MODEL-IDI, FWO Grant 30826052), the Research Foundation Flanders (FWO) research grants (G.0E04.16N, G.0C76.18N, G.0B71.18N, G.0B96.20N), Methusalem (BOF16/ MET_V/007), iBOF20/IBF/039 ATLANTIS, Foundation against Cancer (FAF-F/2016/865, F/2020/1505, F/2020/1434), the Cancer Research Institute Ghent (CRIG) and the Ghent Gut Inflammation Group (GGIG) consortia, and the Flanders Institute for Biotechnology (VIB). E.D.S. acknowledges funding by Excellence of Science EOS MODEL-IDI (FWO Grant 30826052), Foundation against cancer (FAF-F/2016/865) and Methusalem (BOF16/MET_V/007). K.B. gratefully acknowledges the funding by the European Research Council (ERC) under the European Union's Horizon 2020 research and innovation program (grant no. 648124). J.R. and C.D.T. acknowledge funding of the Research Foundation Flanders (FWO, Grant nos. 1110721N and 12 S $9418 \mathrm{~N}$, respectively). We thank Yves Dondelinger and Benjamin Cappe for their contribution to the rebuttal.

Author contributions Conceptualization, EDS, JR, SS, FBR, KB and PV; methodology, EDS, JR, BP, SS, FBR, KB and PV; validation, EDS, JR, FBR, KB and PV; formal analysis, EDS, JR, BP and CDT; investigation, EDS and JR; resources, EDS, JR, FBR, KB and PV; data curation, EDS and JR; writing - original draft, EDS and JR; writingreview and editing, EDS, JR, BP, CDT, SS, KR, KOB, WD, FBR, KB and PV; visualization, EDS and JR; supervision, SS, KR, WD, FBR, $\mathrm{KB}$ and $\mathrm{PV}$; project administration, EDS and JR; funding acquisition, $\mathrm{JR}, \mathrm{KB}$ and $\mathrm{PV}$

Availability of data and material The datasets generated during and/or analyzed during the current study are available from the corresponding author on reasonable request.

Code availability Not applicable.

\section{Declarations}

Conflict of interests The authors declare that there are no competing interests.

Ethics approval Not applicable.

Consent to participate Not applicable.

Consent for publication Not applicable.

Open Access This article is licensed under a Creative Commons Attribution 4.0 International License, which permits use, sharing, adaptation, distribution and reproduction in any medium or format, as long as you give appropriate credit to the original author(s) and the source, provide a link to the Creative Commons licence, and indicate if changes were made. The images or other third party material in this article are included in the article's Creative Commons licence, unless indicated otherwise in a credit line to the material. If material is not included in the article's Creative Commons licence and your intended use is not permitted by statutory regulation or exceeds the permitted use, you will 
need to obtain permission directly from the copyright holder. To view a copy of this licence, visit http://creativecommons.org/licenses/by/4.0/.

\section{References}

1. Green DR, Oguin TH, Martinez J (2016) The clearance of dying cells: table for two. Cell Death Differ 23:915-926. https://doi.org/ 10.1038/cdd.2015.172

2. Vanden Berghe T, Vanden VN, Parthoens E et al (2010) Necroptosis, necrosis and secondary necrosis converge on similar cellular disintegration features. Cell Death Differ 17:922-930. https://doi. org/10.1038/cdd.2009.184

3. Boeltz S, Hagen M, Knopf J et al (2019) Towards a pro-resolving concept in systemic lupus erythematosus. Semin Immunopathol 41:681-697

4. Nagata S (2018) Apoptosis and clearance of apoptotic cells. Annu Rev Immunol 36:489-517. https://doi.org/10.1146/annur ev-immunol-042617-053010

5. Sachet M, Liang YY, Oehler R (2017) The immune response to secondary necrotic cells. Apoptosis 22:1189-1204. https://doi. org/10.1007/s10495-017-1413-Z

6. De Schutter E, Roelandt R, Riquet FB et al (2021) Punching holes in cellular membranes: biology and evolution of gasdermins. Trends Cell Biol. https://doi.org/10.1016/j.tcb.2021.03. 004

7. Broz P, Pelegrín P, Shao F (2019) The gasdermins, a protein family executing cell death and inflammation. Nat Rev Immunol

8. Liu X, Xia S, Zhang Z et al (2021) Channelling inflammation: gasdermins in physiology and disease. Nat Rev Drug Discov 20:384-405. https://doi.org/10.1038/S41573-021-00154-Z

9. Kayagaki N, Stowe IB, Lee BL et al (2015) Caspase-11 cleaves gasdermin D for non-canonical inflammasome signalling. Nature 526:666-671. https://doi.org/10.1038/nature15541

10. Shi J, Zhao Y, Wang K et al (2015) Cleavage of GSDMD by inflammatory caspases determines pyroptotic cell death. Nature 526:660-665. https://doi.org/10.1038/nature15514

11. He W, Wan H, Hu L et al (2015) Gasdermin D is an executor of pyroptosis and required for interleukin- $1 \beta$ secretion. Cell Res 25:1285-1298. https://doi.org/10.1038/cr.2015.139

12. Rogers C, Fernandes-Alnemri T, Mayes L et al (2017) Cleavage of DFNA5 by caspase-3 during apoptosis mediates progression to secondary necrotic/pyroptotic cell death. Nat Commun 8:14128. https://doi.org/10.1038/ncomms 14128

13. Rogers C, Erkes DA, Nardone A et al (2019) Gasdermin pores permeabilize mitochondria to augment caspase-3 activation during apoptosis and inflammasome activation. Nat Commun 10:1689. https://doi.org/10.1038/s41467-019-09397-2

14. Ding J, Wang K, Liu W et al (2016) Pore-forming activity and structural autoinhibition of the gasdermin family. Nature 535:111116. https://doi.org/10.1038/nature18590

15. Op de Beeck K, Van Camp G, Thys S et al (2011) The DFNA5 gene, responsible for hearing loss and involved in cancer, encodes a novel apoptosis-inducing protein. Eur J Hum Genet 19:965-973. https://doi.org/10.1038/ejhg.2011.63

16. Lee BL, Mirrashidi KM, Stowe IB et al (2018) ASC- and caspase8-dependent apoptotic pathway diverges from the NLRC4 inflammasome in macrophages. Sci Rep 8:3788. https://doi.org/10.1038/ s41598-018-21998-3

17. Tixeira R, Shi B, Parkes MAF et al (2018) Gasdermin E does not limit apoptotic cell disassembly by promoting early onset of secondary necrosis in Jurkat T cells and THP-1 monocytes. Front Immunol 9:2842. https://doi.org/10.3389/fimmu.2018.02842
18. Liu X, Zhang Z, Ruan J et al (2016) Inflammasome-activated gasdermin D causes pyroptosis by forming membrane pores. Nature 535:153-158. https://doi.org/10.1038/nature18629

19. Ruan J, Xia S, Liu X et al (2018) Cryo-EM structure of the gasdermin A3 membrane pore. Nature 557:62-67. https://doi.org/10. 1038/s41586-018-0058-6

20. Xia S, Zhang Z, Magupalli VG et al (2021) Gasdermin D pore structure reveals preferential release of mature interleukin-1. Nature. https://doi.org/10.1038/s41586-021-03478-3

21. Mulvihill E, Sborgi L, Mari SA et al (2018) Mechanism of membrane pore formation by human gasdermin-D. EMBO J 2018:e98321. https://doi.org/10.15252/embj.201798321

22. Sborgi L, Rühl S, Mulvihill E et al (2016) GSDMD membrane pore formation constitutes the mechanism of pyroptotic cell death. EMBO J 35:1766-1778. https://doi.org/10.15252/embj.20169 4696

23. Fraire JC, Houthaeve G, Liu J et al (2020) Vapor nanobubble is the more reliable photothermal mechanism for inducing endosomal escape of siRNA without disturbing cell homeostasis. J Control Release 319:262-275. https://doi.org/10.1016/j.jconrel.2019.12. 050

24. Xiong R, Joris F, Liang S et al (2016) Cytosolic delivery of nanolabels prevents their asymmetric inheritance and enables extended quantitative in vivo cell imaging. Nano Lett 16:5975-5986. https://doi.org/10.1021/acs.nanolett.6b01411

25. Xiong R, Raemdonck K, Peynshaert K et al (2014) Comparison of gold nanoparticle mediated photoporation: vapor nanobubbles outperform direct heating for delivering macromolecules in live cells. ACS Nano 8:6288-6296. https://doi.org/10.1021/nn501 7742

26. Raes L, Stremersch S, Fraire JC et al (2020) Intracellular delivery of mRNA in adherent and suspension cells by vapor nanobubble photoporation. Nano-Micro Lett 12:1-17. https://doi.org/10.1007/ s40820-020-00523-0

27. Ramon J, Xiong R, De Smedt SC et al (2021) Vapor nanobubble-mediated photoporation constitutes a versatile intracellular delivery technology. Curr Opin Colloid Interface Sci 54:101453. https://doi.org/10.1016/j.cocis.2021.101453

28. Liu J, Xiong R, Brans T et al (2018) Repeated photoporation with graphene quantum dots enables homogeneous labeling of live cells with extrinsic markers for fluorescence microscopy. Light Sci Appl 7:2047-7538. https://doi.org/10.1038/s41377-018-0048-3

29. Wayteck L, Xiong R, Braeckmans K et al (2017) Comparing photoporation and nucleofection for delivery of small interfering RNA to cytotoxic T cells. J Control Release 267:154-162. https:// doi.org/10.1016/j.jconrel.2017.08.002

30. Lukianova-Hleb E, Hu Y, Latterini L et al (2010) Plasmonic nanobubbles as transient vapor nanobubbles generated around plasmonic nanoparticles. ACS Nano 4:2109-2123. https://doi.org/10. $1021 / \mathrm{nn} 1000222$

31. Hodgkins A, Farne A, Perera S et al (2015) WGE: a CRISPR database for genome engineering. Bioinformatics 31:3078-3080. https://doi.org/10.1093/bioinformatics/btv308

32. Brinkman EK, Chen T, Amendola M, van Steensel B (2014) Easy quantitative assessment of genome editing by sequence trace decomposition. Nucleic Acids Res 42:e168-e168. https://doi.org/ 10.1093/nar/gku936

33. De Groote P, Grootjans S, Lippens S et al (2016) Generation of a new Gateway-compatible inducible lentiviral vector platform allowing easy derivation of co-transduced cells. Biotechniques 60:252-259. https://doi.org/10.2144/000114417

34. Raes L, Van Hecke C, Michiels J et al (2019) Gold nanoparticlemediated photoporation enables delivery of macromolecules over a wide range of molecular weights in human CD4+ T cells. Curr Comput-Aided Drug Des 9:411. https://doi.org/10.3390/cryst 9080411 
35. Hothorn T, Bretz F, Westfall P (2008) Simultaneous inference in general parametric models. Biometrical J 50:346-363

36. R Core Team (2020) R: a language and environment for statistical computing. In: R Found. Stat. Comput. https://www.r-project.org/. Accessed 10 Apr 2021

37. Vercammen D, Vandenabeele P, Beyaert R et al (1997) Tumour necrosis factor-induced necrosis versus anti-Fas-induced apoptosis in L929 cells. Cytokine 9:801-808. https://doi.org/10.1006/ CYTO.1997.0252

38. Vercammen D, Brouckaert G, Denecker G et al (1998) Dual signaling of the Fas receptor: initiation of both apoptotic and necrotic cell death pathways. J Exp Med 188:919-930

39. Vanden Berghe T, Grootjans S, Goossens V et al (2013) Determination of apoptotic and necrotic cell death in vitro and in vivo. Methods 61:117-129. https://doi.org/10.1016/J.YMETH.2013.02. 011

40. De SE, Cappe B, Wiernicki B et al (2021) Plasma membrane permeabilization following cell death: many ways to dye! Cell Death Discov 71(7):1-3. https://doi.org/10.1038/s41420-021-00545-6

41. Wang Y, Gao W, Shi X et al (2017) Chemotherapy drugs induce pyroptosis through caspase-3 cleavage of a gasdermin. Nature 547:99-103. https://doi.org/10.1038/nature22393

42. Lénárt $\mathrm{P}$, Ellenberg $\mathrm{J}$ (2006) Monitoring the permeability of the nuclear envelope during the cell cycle. Methods 38:17-24. https:// doi.org/10.1016/j.ymeth.2005.07.010

43. Galluzzi L, Kroemer G (2017) Secondary necrosis: accidental no more. Trends Cancer 3:1-2. https://doi.org/10.1016/J.TRECAN. 2016.12.001

44. Zhang Z, Zhang Y, Xia S et al (2020) Gasdermin E suppresses tumour growth by activating anti-tumour immunity. Nature 579:16. https://doi.org/10.1038/s41586-020-2071-9

45. Hochreiter-Hufford A, Ravichandran KS (2013) Clearing the dead: apoptotic cell sensing, recognition, engulfment, and digestion.
Cold Spring Harb Perspect Biol. https://doi.org/10.1101/cshpe rspect.a008748

46. Elliott MR, Ravichandran KS (2016) The dynamics of apoptotic cell clearance. Dev Cell 38:147-160

47. Ravichandran KS, Lorenz U (2007) Engulfment of apoptotic cells: Signals for a good meal. Nat Rev Immunol 7:964-974

48. Lövgren T, Eloranta ML, Båve U et al (2004) Induction of interferon- $\alpha$ production in plasmacytoid dendritic cells by immune complexes containing nucleic acid released by necrotic or late apoptotic cells and lupus IgG. Arthritis Rheum 50:1861-1872. https://doi.org/10.1002/art.20254

49. Evavold CL, Ruan J, Tan Y et al (2018) The pore-forming protein gasdermin D regulates interleukin-1 secretion from living macrophages. Immunity 48:35-44.e6. https://doi.org/10.1016/J. IMMUNI.2017.11.013

50. Heilig R, Dick MS, Sborgi L et al (2018) The gasdermin-D pore acts as a conduit for IL- $1 \beta$ secretion in mice. Eur J Immunol 48:584-592. https://doi.org/10.1002/eji.201747404

51. Zhou B, Abbott DW (2021) Gasdermin E permits interleukin-1 beta release in distinct sublytic and pyroptotic phases. Cell Rep 35:108998. https://doi.org/10.1016/j.celrep.2021.108998

52. Kayagaki N, Kornfeld OS, Lee BL et al (2021) NINJ1 mediates plasma membrane rupture during lytic cell death. Nature. https:// doi.org/10.1038/s41586-021-03218-7

Publisher's Note Springer Nature remains neutral with regard to jurisdictional claims in published maps and institutional affiliations. 